\title{
EL ESTADO DE ALARMA EN ESPAÑA Y LA CLÁUSULA DEROGATORIA DEL CONVENIO EUROPEO PARA LA PROTECCIÓN DE LOS DERECHOS HUMANOS Y LAS LIBERTADES FUNDAMENTALES
}

\author{
JORDI BONET PÉREZ
}

¡bonet@ub.edu

\begin{abstract}
Cómo citar/Citation
Bonet Pérez, J. (2020).

El estado de alarma en España y la cláusula derogatoria del Convenio Europeo para la Protección de los Derechos Humanos y las Libertades Fundamentales. Revista de Derecho Comunitario Europeo, 67, 873-919. doi: https://doi.org/10.18042/cepc/rdce.67.04
\end{abstract}

\section{Resumen}

El establecimiento del estado de alarma en España debido a la pandemia de COVID-19 (Real Decreto 463/2020) no ha comportado, a nivel jurídico internacional, la invocación de la cláusula derogatoria del art. 15 del Convenio para la Protección de los Derechos Humanos y de las Libertades Fundamentales (CEDH) para amparar las medidas que afectan a los derechos y libertades reconocidos en el CEDH y sus protocolos. Otros diez Estados partes, en cambio, lo han hecho. Este hecho es relevante, primero, porque los parámetros interpretativos que mantiene el Tribunal Europeo de Derechos Humanos (TEDH) no descartan que la crisis sanitaria sea una amenaza excepcional que permita invocar la cláusula derogatoria. Y, segundo, porque no es fácil dirimir si las medidas anticrisis españolas responden a los estándares de necesidad y proporcionalidad de las restricciones ordinarias previstas en las disposiciones específicas del CEDH y sus protocolos (adecuadas para períodos de normalidad democrática) o si lo hacen adecuándose a los estándares derogatorios del art. 15 CEDH. Un análisis prospectivo, comparativo con otros Estados partes pero también específico de la práctica española, muestra cómo es factible que se compaginen ambas

1 Catedrático de Derecho Internacional Público, Universidad de Barcelona. 
tipologías. Esto puede tener consecuencias jurídicas en el caso de que se presenten demandas ante el TEDH: si un Estado como España no ha notificado haber recurrido a la cláusula derogatoria, verá cómo todas sus medidas serán juzgadas conforme a los estándares de necesidad y proporcionalidad de las restricciones ordinarias, aunque por su configuración se aproximen a las medidas derogatorias.

\section{Palabras clave}

COVID-19; crisis sanitarias; cláusula derogatoria; restricciones ordinarias; Tribunal Europeo de Derechos Humanos; estado de alarma.

\section{THE STATE OF ALARM IN SPAIN AND THE DEROGATORY CLAUSE OF THE EUROPEAN CONVENTION ON THE PROTECTION OF HUMAN RIGHTS AND FUNDAMENTAL FREEDOMS}

\section{Abstract}

The declaration of the state of alarm in Spain (Royal Decree 463/2020) due to the COVID-19 pandemic has not, at the international legal level, been accompanied by invoking the derogation clause set out in Art. 15 of the European Convention on the protection of Human rights and Fundamental freedoms (ECHR) so as to legitimize measures affecting the rights and freedoms recognized in the ECHR and its Protocols. However, ten other States Parties have done so. This is relevant because the interpretative criteria maintained by the European Court of Human Rights (ECtHR) do not exclude sanitary crises from constituting an exceptional threat that allows the derogation clause to be invoked. Additionally, it is not easy to say whether the Spanish measures comply with standards of necessity and proportionality of the ordinary restrictions provided for in the specific provisions of the Convention and its Protocols (appropriate in times of democratic normalcy) or if they do so in accordance with Art. 15 ECHR. A prospective analysis, comparing other States Parties but also specific to Spanish practice, shows how it is feasible for both categories of measures to be combined. This may have legal consequences in the event of lawsuits before the ECtHR: if a State such as Spain has not notified that it has resorted to the derogation clause, all its measures will be judged in accordance with the standards of necessity and proportionality of ordinary restrictions although by their configuration some of them seem to be close to derogating measures.

\section{Keywords}

COVID-19; sanitary crisis; derogatory clause; ordinary restrictions; European Court of Human Rights; state of alarm. 


\section{L'ÉTAT D'ALARME EN ESPAGNE ET LA CLAUSE DÉROGATOIRE DE LA CONVENTION EUROPÉENNE DE SAUVEGARDE DES DROITS DE L'HOMME ET DES LIBERTÉS FONDAMENTALES}

\section{Résumé}

La mise en place de l'état d'alarme en Espagne en raison de la pandémie de COVID-19 (décret royal 463/2020) n'a pas conduit, au niveau juridique international, à l'invocation de la clause dérogatoire de l'art. 15 de la Convention européenne de sauvegarde des droits de l'homme et des libertés fondamentales (CEDH) pour couvrir les mesures affectant les droits et libertés reconnus par la $\mathrm{CEDH}$ et ses protocoles. Dix autres États parties, en revanche, l'ont fait. Cela est pertinent, d'abord, car les paramètres interprétatifs maintenus par la Cour européenne des droits de l'homme (CrE) n'excluent pas le fait que la crise sanitaire constitue une menace exceptionnelle qui permet d'invoquer la clause dérogatoire. Deuxièmement, parce qu'il n'est pas facile de dire si les mesures espagnoles répondent aux principes de nécessité et de proportionnalité des restrictions ordinaires prévues dans les dispositions spécifiques de la $\mathrm{CEDH}$ et de ses Protocoles (appropriées pour les périodes de normalité démocratique) ou si elles le font conformément aux normes dérogatoires de l'art. 15 de la $\mathrm{CEDH}$. Une analyse prospective, comparative avec d'autres États parties mais aussi spécifique à la pratique espagnole, montre comment il est possible de combiner les deux typologies. Cela peut avoir des conséquences juridiques en cas de procès devant la CrE: si un État comme l'Espagne n'a pas informé du recours à la clause d'abrogation, il verra comment toutes ses mesures seront jugées selon les principes de nécessité et de proportionnalité des restrictions ordinaires, même si, par leur configuration, ils se rapprochent des mesures d'abrogation.

\section{Mots clés}

COVID-19; crise sanitaire; clause dérogatoire; restrictions ordinaires; Cour européenne des droits de l'homme; état d'alarme. 


\section{SUMARIO}

I. INTRODUCCIÓN. II. LA CALIFICACIÓN O NO DE LA CRISIS SANITARIA EN ESPAÑA COMO EXCEPCIONAL DESDE EL PRISMA DEL ARTíCULO 15 CEDH: 1. Los parámetros interpretativos para la identificación de una amenaza excepcional en el artículo $15 \mathrm{CEDH}$. 2. La aplicabilidad o no del artículo $15 \mathrm{CEDH}$ a la crisis sanitaria ocasionada por la COVID-19. III. LAS MEDIDAS ADOPTADAS PARA COMBATIR LA CRISIS SANITARIA Y SU COMPATIBILIDAD CON EL CEDH Y SUS PROTOCOLOS: 1. Los efectos jurídicos del cumplimiento de la obligación de notificación conforme al artículo 15.3 CEDH. 2. La tipología de medidas adoptadas por los Estados partes frente a la COVID-19. 3. La especificidad de la práctica española respecto a la COVID-19. IV. CONSIDERACIONES FINALES. BIBLIOGRAFía.

\section{INTRODUCCIÓN}

Más allá de la magnitud de las consecuencias humanas, sociales y económicas derivadas de la extensión en España de la COVID-19, la adopción y entrada en vigor del Real Decreto 463/2020, de 14 de marzo, por el que se declara el estado de alarma para la gestión de la situación de crisis sanitaria ocasionada por el COVID-19 (RD 463/2020) ${ }^{2}$, junto al resto de disposiciones normativas complementarias, desarrolla un bloque normativo excepcional —al amparo de la habilitación otorgada por el art. 116 de la Constitución Española (CE) y la Ley Orgánica 4/1981, de 1 de junio, de los estados de alarma, excepción y sitio- cuyo fundamento y alcance suscitan diversos interrogantes jurídicos. La dimensión internacional no es ajena al debate jurídico; sobre todo, debido a la potencial repercusión de su aplicación sobre la efectividad del goce y disfrute de los derechos humanos internacionalmente reconocidos que vinculan a España. Esta afectación puede medirse y analizarse desde la perspectiva tanto de las limitaciones al ejercicio de ciertos derechos humanos necesarias para superar la crisis sanitaria (si es que no lo es la suspensión/derogación temporal), como de las medidas que garanticen en este período disruptivo que las personas puedan ver respetados, conforme a los márgenes y las adaptaciones que la situación de hecho exija, sus derechos

2 BOE, Núm. 67, de 14 de marzo de 2020. 
humanos — piénsese, por ejemplo, en las obligaciones jurídicas concernientes a ciertos derechos económicos, sociales y culturales-.

Si este asunto se focaliza de modo principal en las limitaciones al ejercicio de los derechos humanos internacionalmente reconocidos o en su suspensión/derogación temporal —opciones ambas previstas en el derecho internacional de los derechos humanos (DIDH) - , cabe partir de la idea de que la Organización Mundial de la Salud (OMS) consideró el 11 de marzo de 2020, tal y como comunicó su director general, que la COVID-19 era una pandemia ${ }^{3}$, aleccionando a los Estados a adoptar «medidas urgentes y agresivas» (OMS, 2020).

A este toque de atención, al que caben añadir las previas experiencias de otros países, han ido respondiendo España y otros Estados europeos, adoptando decisiones políticas y jurídicas crecientemente intensivas y excepcionales — siguiendo al Director General de la OMS, más agresivas—, en función de la extensión interna de la enfermedad y, debe suponerse, de las propuestas de los asesores técnicos. En España, el RD 463/2020 parte de la existencia de una situación de emergencia sanitaria (art. 1), que en su exposición de motivos tilda de "grave y excepcional», y, frente a la cual, es «indispensable proceder a la declaración del estado de alarma». El objetivo del RD 463/2020 es intensificar sin demora las «medidas temporales de carácter extraordinario que ya se han adoptado», para prevenir y contener el virus y mitigar su impacto sanitario, social y económico.

La entidad de la emergencia sanitaria, según el RD 463/2020, perfila un escenario en el que el desarrollo normativo tiende a separarse de los parámetros político-jurídicos propios de las normas jurídicas aplicables en períodos ordinarios de normalidad democrática, cuando no existen riesgos extraordinarios que amenacen la estabilidad institucional, la paz social y/o la vida de las personas bajo la jurisdicción estatal. Esta dirección político-jurídica es identificable en el art. 1.1 Ley Orgánica 4/1981, en la que, sin diferenciación todavía entre los tres supuestos previstos —alarma, excepción y sitio-, se afirma que procederá declarar una u otra institución jurídica "cuando circunstancias extraordinarias hiciesen imposible el mantenimiento de la normalidad mediante los poderes ordinarios de las Autoridades competentes» (la cursiva es propia).

3 «Enfermedad epidémica que se extiende a muchos países o que ataca a casi todos los individuos de una localidad o región» (Real Academia Española. Diccionario de la lengua española, 23. a ed., [versión 23.3 en línea]. Disponible en: https://dle.rae.es. Acceso 2 de junio 2020). 
El objeto de este estudio es el análisis de la efectiva o no adecuación de las medidas adoptadas en y a partir del RD 463/2020 a lo prescrito en el Convenio Europeo para la Protección de los Derechos Humanos y Libertades, de 4 de noviembre (CEDH), y en sus protocolos, planteando la compatibilidad de lo dispuesto a partir de 14 de marzo de 2020 con las facultades de restricción o derogación que el CEDH y sus protocolos ofrecen para que el Estado salvaguarde el interés público. La hipótesis de trabajo se centra en la posibilidad de que, aun cuando España no haya invocado la cláusula derogatoria del art. 15 del CEDH, es admisible (o no) que las medidas adoptadas excedan en la práctica del marco jurídico de las restricciones ordinarias permitidas por el CEDH y se identifiquen desde el prisma material, total o parcialmente, con los poderes de excepción disponibles conforme al art. 15 $\mathrm{CEDH}$; lo cual, asimismo, supone reflexionar respecto a las potenciales consecuencias jurídicas de no recurrir a la habilitación del art. $15 \mathrm{CEDH}$ cuando es factible considerar que se ha ido más allá de las restricciones ordinarias.

Esta opción selectiva, que no excluirá referencias a otros tratados internacionales de carácter general sobre derechos humanos de los que España es parte ${ }^{4}$, se justifica: 1) por el hecho de que, junto a España, otros Estados europeos y miembros del Consejo de Europa hayan tendido a adoptar medidas tendencialmente excepcionales, aunque hayan discrepado en cómo calificar su rumbo político-jurídico conforme al marco jurídico perfilado por el CEDH y sus protocolos; y 2) por la importancia cualitativa que para los ordenamientos jurídicos internos de los Estados miembros del Consejo de Europa - y, por ello, partes del CEDH - tienen la opinión y las decisiones jurisdiccionales del Tribunal Europeo de Derechos Humanos (TEDH), contando con que su jurisprudencia ha abordado previamente asuntos relativos a crisis excepcionales.

La aproximación sugerida parte de que, dentro de los tratados internacionales de derechos humanos de carácter general, el CEDH manifiesta una de las tendencias principales sobre cómo habilitar al Estado para activar los denominados poderes de crisis (United Nations, 1982: 8, párr. 22) o excepcionales: el modelo de acomodación ${ }^{5}$.

4 Su objeto es, a escala universal y regional, formular el reconocimiento jurídico internacional de un determinado catálogo de derechos humanos e incorporar adicionalmente mecanismos de garantía internacionales.

5 Frente al modelo Business Are Usual que propugna que «a state of emergency is not deemed to justify a deviation from the 'normal' legality» (Gross y Oren, 2006: 252), expresado, dentro del DIDH, en la presencia exclusiva de técnicas jurídicas de limitación (excepciones y/o cláusulas restrictivas) en tratados internacionales de carácter general como el Pacto Internacional de Derechos Económicos, Sociales y Culturales, 
El CEDH dispone de una cláusula de habilitación (cláusula derogatoria) que traslada la previa experiencia jurídica de los modelos de acomodación internos que prevén «a legal emergency system» (Gross y Oren, 2006: 255), compuesto de instituciones preconfiguradas jurídicamente y sintetizadas de manera genérica en la figura del estado de excepción (Naciones Unidas, 1997: 8, párr. 20) ${ }^{6}$. La cláusula derogatoria faculta al Estado a tomar medidas excepcionales, consistentes en la derogación de determinados derechos y libertades, siempre que se produzca una circunstancia suficientemente grave como para ser calificada de excepcional en los términos de la cláusula derogatoria (amenaza excepcional), y, además, se respeten las condiciones jurídicas para ello establecidas.

Contienen también cláusulas derogatorias el art. 4 del Pacto Internacional de Derechos Civiles y Políticos, de 16 de diciembre de 1966 (PIDCP); el art. 27 de la Convención Americana de Derechos Humanos, de 22 de noviembre de 1969 (CADH); y el art. 4 de la Carta Árabe de Derechos Humanos, de 24 de mayo de 2004. Además del art. $15 \mathrm{CEDH}$, es incorporada por el art. $30 \mathrm{de}$ la Carta Social Europea, de 18 de octubre de 1961 (CSE), y por el articulo F de la Carta Social Europea Revisada, de 3 de mayo de 1996 (CSE revisada) ${ }^{7}$.

Teóricamente, podría pensarse que siempre la cláusula derogatoria se corresponde a nivel internacional con lo que en el ordenamiento jurídico interno son las legislaciones o poderes latentes excepcionales - por ejemplo, los previstos en el art. $116 \mathrm{CE}$ - . No obstante, la práctica internacional muestra cómo el recurso a las cláusulas derogatorias también se ha fundamentado cuando el Estado opera sobre la base legal ordinaria y la capacidad potencial de su modificación por razones excepcionales conforme al principio de legalidad.

de 16 de diciembre de 1966, o la Carta Africana de los Derechos del Hombre y de los Pueblos, de 27 de julio de 1981.

6 Expresión que abarcaría «el conjunto de situacions cubiertas por los términos: "estado de emergencia”, "estado de sitio", "estado de urgencia", "estado de alarma”, "estado de prevención”, "estado de guerra interna”, "suspensión de garantías”, "ley marcial”, "poderes de crisis", "poderes especiales", "toque de queda”, etc. y todas aquellas medidas adoptadas por los gobiernos que impliquen restricciones al ejercicio de los derechos humanos que superen aquellas regularmente autorizadas en situaciones ordinarias» (Naciones Unidas, 1997: 8, párr. 20).

7 España es parte de la CSE y no de la CSE revisada (BOE, núm. 153, de 26 de junio de 1980; corrección de errores en $B O E$, núm. 192, de 11 de agosto de 1980); España denunció el art. 8.4.(b) de la CSE con efectos de 5 de junio de 1991 (BOE, núm. 112, de 10 de mayo de 1991). 
La habilitación que convencionalmente otorga una cláusula derogatoria al Estado parte presupone que este debe recurrir a ella ciñéndose a siete principios (Oraá Oraá, 1992: 260-265): 1) el de la existencia de una crisis excepcional (sea cual sea la calificación nominal convencional); 2) el de la inderogabilidad de ciertos derechos y libertades (que la cláusula derogatoria y ocasionalmente otras disposiciones del tratado internacional o de sus protocolos adicionales identifican expresamente); 3) el de proporcionalidad (las medidas deben estrictamente adecuarse a la situación: lo que restringe implícitamente la posibilidad de derogar en toda su extensión otros derechos humanos reconocidos, por ejemplo, las garantías judiciales mínimas); 4) el de no discriminación; 5) el de conformidad con otras obligaciones jurídicas internacionales aplicables (por ejemplo, en caso de conflicto armado, las del Derecho internacional humanitario); 6) el de la proclamación de conformidad con las normas jurídicas internas; y 7) el de la notificación al depositario del tratado internacional ${ }^{8}$. En definitiva, las cláusulas derogatorias son un intento de constreñir en lo posible la conducta estatal en períodos de emergencia (Sottiaux, 2018: 1075).

La cláusula derogatoria del CEDH se encuentra en su art. 15:

1. En caso de guerra o de otro peligro público que amenace la vida de la nación, cualquier Alta Parte Contratante podrá tomar medidas que deroguen las obligaciones previstas en el presente Convenio en la medida estricta en que lo exija la situación, y supuesto que tales medidas no estén en contradicción con las otras obligaciones que dimanan del Derecho internacional.

2. La disposición precedente no autoriza ninguna derogación al artículo 2 [derecho a la vida], salvo para el caso de muertes resultantes de actos lícitos de guerra, y a los artículos 3 [prohibición de la tortura y otras prácticas análogas], 4 (párrafo 1) [prohibición de la esclavitud y la servidumbre] y 7 [no hay pena sin ley] ${ }^{9}$.

8 Admitiendo este autor que el derecho internacional general contempla también medidas de acomodación equivalentes a la cláusula derogatoria, señala que, si no todos, se incorporan a este ámbito normativo al menos cuatro de los principios reseñados: el principio de la existencia de una amenaza excepcional, el principio de proporcionalidad, el principio de no discriminación y el principio de inderogabilidad. Destaca la particular dificultad de clarificar qué derechos considera inderogables el derecho internacional general —cuestión abierta pese a que constituya un «achievement of civilization» (Cançado-Trindade, 1996: 88)-.

9 Son también inderogables: art. 3 del Protocolo núm. 6 y el art. 2 del Protocolo núm. 13, ambos relativos a la pena de muerte, así como el art. 4 del Protocolo núm. 7 (derecho a no ser juzgado o condenado dos veces). 
3. Toda Alta Parte Contratante que ejerza este derecho de derogación tendrá plenamente informado al Secretario General del Consejo de Europa de las medidas tomadas y de los motivos que las han inspirado. Deberá igualmente informar al Secretario general del Consejo de Europa de la fecha en que esas medidas hayan dejado de estar en vigor y las disposiciones del Convenio vuelvan a tener plena aplicación».

Esta cláusula derogatoria convive en el marco convencional con excepciones ${ }^{10}$ y cláusulas restrictivas ${ }^{11}$ que técnica y político-jurídicamente delimitan el espacio de injerencia estatal sobre los derechos y libertades reconocidos. Aunque el art. $15 \mathrm{CEDH}$ habilite a derogar sus obligaciones jurídicas relativas a ciertos derechos y libertades dentro de los parámetros legales de su redactado, un Estado Parte puede decidir no prevalerse de la cláusula derogatoria - porque no hacerlo no significa que los Estados parte «haven't taken exceptional measures, but that they refused to use that mechanism» (Toullier, 2017: 10) — Esta opción jurídica implica presumir que las medidas anticrisis se adoptan conforme a los instrumentos jurídicos ordinarios de injerencia previstos en el CEDH y sus protocolos, aunque objetivamente la situación de hecho pueda encajar por su gravedad en la descripción del art. 15.1 CEDH. Esto tendrá consecuencias jurídicas, sobre todo en el terreno de la ponderación del ejercicio de los poderes para atajar la crisis, es decir, al examinar la legislación y la práctica subsiguientes; particularmente, cuando se proceda a ella a través de la supervisión jurisdiccional que pueda derivarse del acceso de los particulares u otros Estados partes al TEDH.

La observación de la práctica que, hasta ahora, han seguido los Estados partes al abordar la expansión de la COVID-19 manifiesta dos tendencias: de un lado, están aquellos que han optado por acudir a la cláusula derogatoria para legitimar el conjunto de las medidas anticrisis adoptadas (diez Estados partes) ${ }^{12}$; y, de otro lado, los que no parecen considerar necesario dar ese paso y creen ajustado su comportamiento a las excepciones y cláusulas restric-

10 Por ejemplo, el art. 5.1 CEDH, tras reconocer el derecho a la libertad y la seguridad, enumera una serie de supuestos en que conforme a la ley una persona puede ser privada de libertad.

11 Tras conceptualizar un derecho o libertad, en otro párrafo se disponen las condiciones bajo las cuales el Estado Parte puede injerirse en el ejercicio de un derecho o libertad específico: previsión legal de la injerencia, finalidad legítima y necesidad en la sociedad democrática (véase, por ejemplo, art. $9 \mathrm{CEDH}$ ).

12 Los Estados partes que han invocado la cláusula derogatoria son: Albania, Armenia, Estonia, Georgia, Letonia, Macedonia del Norte, República de Moldavia, Rumania, San Marino y Serbia. El contenido de las diez notificaciones conforme al art. 15.3 CEDH (Council of Europe, 2020a). 
tivas previstas en el CEDH y sus protocolos (37 Estados partes). Entre estos últimos parece encontrarse España, a pesar de los términos que expresa el RD 463/2020 y de que las medidas adoptadas se fundamentan en un poder latente y constitucional ante circunstancias extraordinarias.

La apreciación de la idoneidad de la práctica española, en el contexto de las respuestas estatales europeas frente a la COVID-19, respecto a la cláusula derogatoria - $\mathrm{y}$, en general, al CEDH y sus protocolos- comportará examinar dos elementos derivados de la hipótesis inicial: 1) la calificación o no de la crisis sanitaria en España como excepcional desde el prisma del art. $15 \mathrm{CEDH}$ (apdo. II), a partir de la descripción de qué debe interpretarse como una amenaza excepcional conforme al art. $15 \mathrm{CEDH}$ (epígrafe II.1) y de la determinación de si una crisis sanitaria como la generada puede ser una amenaza excepcional (epígrafe II.2); y 2) el examen de las medidas adoptadas para combatir la crisis sanitaria y su compatibilidad con el CEDH y sus protocolos (apdo. III), para, partiendo de las obligaciones jurídico-formales del art. $15 \mathrm{CEDH}$-incluidas las relativas al momento de la notificación del recurso a la cláusula derogatoria - (epígrafe III.1), examinar si las medidas adoptadas por otros Estados partes y por España de modo particular constituyen o no medidas excepcionales en el sentido de la cláusula derogatoria (epígrafes III. 2 y 3 ).

Previamente, parece pertinente señalar que: 1) el TEDH define y delimita autónomamente, para el conjunto de Estados partes, la noción de amenaza excepcional inserta en el art. $15 \mathrm{CEDH}$, con independencia de su fundamentación político-jurídica en la práctica interna; 2) nada en su jurisprudencia niega al Estado parte la posibilidad de responder a una crisis excepcional dentro de los parámetros jurídicos de las excepciones y restricciones aplicables en períodos de normalidad institucional y social; y 3) el TEDH, atendiendo a la mejor posición de las autoridades estatales para hacer un adecuado balance de intereses — sin perjuicio de su labor de supervisión subsidiaria — concede un "wide margin of appreciation [al Estado] to decide» sobre la existencia de la amenaza excepcional y la naturaleza y alcance de las medidas derogatorias necesarias para abordarla ${ }^{13}$.

\section{LA CALIFICACIÓN O NO DE LA CRISIS SANITARIA EN ESPAÑA COMO EXCEPCIONAL DESDE EL PRISMA DEL ARTíCULO 15 CEDH}

La práctica relativa al art. $15 \mathrm{CEDH}$ perfila unos parámetros interpretativos para la identificación de una amenaza excepcional, siendo este el primer

13 A. and Others v. the United Kingdom [GC], no. 3455/05, párr. 184, ECHR 2009. 
aspecto a abordar en este apartado; el segundo aspecto será la subsiguiente aplicabilidad o no del art. $15 \mathrm{CEDH}$ a la crisis sanitaria ocasionada por la COVID-19.

\section{LOS PARÁMETROS INTERPRETATIVOS PARA LA IDENTIFICACIÓN DE UNA AMENAZA EXCEPCIONAL EN EL ARTÍCULO 15 CEDH}

Como se ha podido ver, una respuesta basada en el art. 15 CEDH tiene un primer condicionante ineludible: la concurrencia de unas circunstancias de hecho que, genéricamente en el contexto del DIDH, se puedan calificar como una amenaza excepcional. La ponderación de su existencia o no evoca, sin entrar por ahora en mayores precisiones jurídicas, una anomalía situacional contingente de extrema gravedad (Gross y Oren, 2006: 251) para el normal desarrollo de la vida social y del funcionamiento de las instituciones públicas. Esto último es significativo puesto que la existencia de una amenaza excepcional no es solo conditio sine qua non para que el Estado parte pueda prevalerse de la cláusula derogatoria, sino la referencia fáctica de la necesidad y del fin de las medidas derogatorias adoptadas (Sudre, 2015: 228). Esto supone, asimismo, ante la conjunción de la percepción de la inicial constatación de su existencia con la voluntad de su progresiva contención y superación, que el ejercicio de los poderes de excepción se perciba como esencialmente temporal (Naciones Unidas, 1997: 19, párr. 69).

Sin dejar de criticar la imprecisión general compartida por todos los instrumentos y de evidenciar sus "variations in terminology» (Fitzpatrick, 1994: 56), la redacción de la cláusula derogatoria en los tratados internacionales que la contienen no difiere excesivamente al definir la amenaza excepcional: mientras el PIDCP se refiere a «situaciones excepcionales (en versión inglesa: public emergency) que pongan en peligro la vida de la nación y cuya existencia haya sido proclamada oficialmente» — de igual forma que el art. 4.1. Carta Árabe de Derechos Humanos ${ }^{14}$-, el/la CEDH/CSE y la $\mathrm{CADH}$ realizan una distinción circunstancial entre situaciones de guerra (conflictos armados internacionales e internos), y aquellas otras circunstancias en que existe un "peligro público que amenace la vida de la nación» —-textos europeos- o bien un «peligro público o de otra emergencia que amenace la independencia o seguridad del Estado parte» -texto americano-. Por su redacción, quizá el texto americano podría resultar más extensivo; no obstante,

14 "In exceptional situations of emergency which threaten the life of the nation and the existence of which is officially proclaimed, the States parties to the present Charter may take measures derogating from their obligations under the present Charter [...]». 
su interpretación ha tendido a equipararlo a los términos de partida de los otros tratados internacionales (Oraá Oraá, 1992: 29) como una situación radicalmente excepcional (Zovatto, 1988: 49).

Junto a su aplicabilidad a los conflictos armados, es lógico entender que la cláusula derogatoria se reserva para situaciones de tal gravedad que, sin llegar a ser equiparables a ellos, generan dificultades excepcionales para el funcionamiento normal de las instituciones estatales o suponen una amenaza de gran calibre para la estabilidad y la paz sociales. Según el Comité de Derechos Humanos, «no todo disturbio o catástrofe constituye una situación excepcional que ponga en peligro la vida de la nación», de modo que los Estados partes del PIDCP «deberán ponderar cuidadosamente el motivo por el cual esa medida es necesaria y legítima en las circunstancias del caso» (Comité de Derechos Humanos, 2001: 1, párr. 3).

Mayor precisión ofrecen los denominados Principios de Siracusa ${ }^{15}$, cuyo Principio 39 perfila la idea de que se trata de: peligros, reales o inminentes, que afectan a toda la población y a todo el territorio estatal o parte de él, amenazando la integridad física de la población, la independencia política o la integridad territorial del Estado, o la existencia y/o funcionamiento básico de las instituciones indispensables para proteger los derechos humanos (Naciones Unidas, 1985: anexo, 5). Es factible conectar esta aproximación con la de los Paris Minimum Standards of Human Rights Norms in a State of Emergency (1976), elaborados por la International Law Association (ILA) ${ }^{16}$, que, ante la posibilidad de que la amenaza excepcional afectase tanto al conjunto de la población como solo a una parte de la misma, refundió el tipo de peligro a una «threat to the organized life of the community of which the state is composed» (Lillich, 1985: 1073, Section A.1 (b)).

Una conceptualización basada en opiniones doctrinales e institucionales previas, aunque particularmente dirigida a abarcar crisis de naturaleza política, entiende la amenaza excepcional como una «serious threat and/or damage to a nation's existence and/or way of life, the temporary (but also uncertain) duration

15 Principios de Siracusa sobre las disposiciones de limitación y derogación del Pacto Internacional de Derechos Civiles y Politicos, traducción del texto original inglés (ONU, 1985: anexo): The Siracusa Principles on the Limitation and Derogation Provisions in the International Covenant on Civil and Political Rights, adopted by the International Conference on the limitation and derogation provisions of the International Covenant on Civil and Political Rights (Siracusa, from 30 April to 4 May 1984).

16 En 2018, la ILA creó un Comité sobre Derechos Humanos en Períodos de Emergencia (ILA Committee on Human Rights in Times of Emergency) cuyo informe intermedio debe presentarse en la Conferencia de Kyoto (pospuesta para celebrarse entre el 29 de noviembre y el 13 de diciembre de 2020). 
of such emergencies, and the marshalling of extraordinary governmental powers and resources to meat such emergencies» (Desierto, 2012: 146).

Todo lo anterior demuestra cómo la aproximación a la noción de amenaza excepcional está muy marcada: 1) por el puro —y deseado- casuismo de las decisiones jurisdiccionales (tribunales) y cuasi-jurisdiccionales (órganos de expertos independientes), no avanzándose de manera consciente en la formulación de modelos o paradigmas descriptivos generales; y 2) por el difícil equilibrio entre la sospecha de actitudes poco cooperativas de algunos Estados y la comprensión de la responsabilidad estatal ante peligros excepcionales. Parece claro que la conceptualización en abstracto no disipa la evidencia de que la «application in concreto of such definition give raise to numerous legal problems» (Svensson-McCarthy, 1998: 185).

La construcción jurisprudencial de la noción de amenaza excepcional quizá más elaborada se ha generado en torno al art. 15.1 del CEDH, a partir de la jurisprudencia del Tribunal Europeo de Derechos Humanos (TEDH) y de la práctica de la desaparecida Comisión Europea de Derechos Humanos (Comisión Europea); precisamente por ello, en buena medida, constituye el referente de las propuestas precitadas.

Los criterios para identificar una amenaza excepcional a tenor del art. $15 \mathrm{CEDH}$ la identifican, con suficiente nitidez según el TEDH (Schabas, 2015: 485), como una situación excepcional de crisis o emergencia que afecta al conjunto de la población y que constituye una amenaza para la vida organizada de la comunidad que compone el Estado ${ }^{17}$.

La Comisión Europea, en el llamado "caso griego", desgranó las características esenciales de la misma a partir de esta caracterización básica ${ }^{18}$ :

- Debe tratarse de una situación actual o inminente - lo que excluiría toda situación esencialmente futura e incierta con visos insuficientes de próxima manifestación-.

- Sus efectos deben afectar al conjunto de la nación — sin perjuicio de su focalización territorial en una zona o zonas concretas del Estado de manera que la afectación real se concentre en una parte de la población-

- Debe constituir una amenaza para la vida organizada de la comunidad: para la pervivencia de las instituciones propias de una sociedad democrática o de la propia comunidad, cuando conforme a las coorde-

17 Lawless v. Ireland (no. 3), 1 July 1961, párr. 28, Series A no. 3.

18 The Greek Case (Denmark, Norway, Sweden and The Netherlands v. Greece), Commission Report of 5 November 1969. Yearbook of the European Convention on Human Rights, 1969 (12bis), p. 70, párr. 113. 
nadas del ejercicio ordinario de los poderes estatales estos se muestran incapaces de contener la crisis. De hecho, las cláusulas derogatorias son un instrumento de expresa diferenciación del régimen jurídico ordinario del de emergencia (Neuman, 2016: 24). La noción de vida de la nación debe ser interpretada restrictivamente; «must imperil some fundamental element of statehood or survival of the population - for example, the functioning of a major constitutional organ, such as judiciary or legislature, or the flow of vital supplies» (Fitzpatrick, 1994: 56)—.

- La amenaza debe ser excepcional, en el sentido de que las medidas o restricciones admitidas por el CEDH para el mantenimiento de la seguridad, la salud y el orden públicos en períodos de normalidad institucional y social resulten claramente inadecuadas, por insuficientes.

La objetivación de los rasgos fundamentales de la noción de amenaza excepcional a través de la interpretación del art. 15.1 CEDH debe completarse con las matizaciones que introduce la sentencia del TEDH en el asunto A. y otros contra el Reino Unido. Aun cuando no elimine la exigencia interpretativa de que "preventative nature are not justified» (El Zeidy, 2003: 284), sí ha ofrecido una interpretación menos rígida de la exigencia de la inminencia de la amenaza excepcional que la apuntada por la Comisión Europea. Ante la calificación por el Estado parte de amenaza excepcional de la situación derivada de los atentados del 11 de septiembre de 2001 en Estados Unidos, el TEDH señaló que el requerimiento de inminencia "cannot be interpreted so narrowly as to require a State to wait for disaster to strike before taking measures to deal with it», ya que es objetivo de la cláusula derogatoria proteger a la población de "future risks», de modo que «the existence of the threat to the life of the nation must be assessed primarily with reference to those facts which were known at the time of the derogation ${ }^{19}$. No es ajena a esta relativización el peso del amplio margen de apreciación otorgado a las autoridades estatales para apreciar el nivel de gravedad de la amenaza existente, pues, a diferencia de los casos relacionados con la situación en Irlanda del Norte (Irlanda y Reino Unido) o el Kurdistán (Turquía), la amenaza terrorista

19 «Although when the derogation was made no al-Qaeda attack had taken place within the territory of the United Kingdom, the Court does not consider that the national authorities can be criticised, in the light of the evidence available to them at the time, for fearing that such an attack was 'imminent', in that an atrocity might be committed without warning at any time» (A. and Others v. the United Kingdom [GC], no. 3455/05, párr. 177, ECHR 2009). 
no es tenida por excepcional por derivar de una real e intensiva campaña de violencia presente sobre el terreno ${ }^{20}$.

Aun cuando el TEDH supervise la motivación de los Estados partes para invocar la cláusula derogatoria, es obvio que otorga un «relatively large margin of appreciation in declaring a state of emergency» (Kadelbach, 2017: 281). La verificación de la importancia paradigmática del margen de apreciación en esta sentencia dentro del conjunto de la jurisprudencia resulta indispensable (Toullier, 2017: 13), puesto que, frente a la evidencia de que el Reino Unido fue el único Estado parte entre los amenazados por Al-Queda que consideró como una amenaza excepcional las derivaciones de los referidos atentados, «the Court accepts that it was for each Government, as the guardian of their own people's safety, to make their own assessment on the basis of the facts known to them ${ }^{21}$.

La amenaza excepcional, en resumen, ha de responder a una situación actual o inminente (se aprecie de un modo más estricto o laxo), de un nivel suficiente de gravedad como para ser calificada de excepcional, entrañando un riesgo muy grave que afecta al conjunto de la población y constituye un peligro para la vida organizada de la nación como tal; de modo que las medidas restrictivas, habituales en períodos de normalidad democrática, resulten insuficientes para solventar la crisis o la emergencia.

La última cuestión jurídica de fondo versa sobre si la emergencia excepcional ha de ser de naturaleza temporal, anclada en la experiencia histórica de los riesgos que los estados de excepción prolongados o permanentes suponen para los derechos humanos (Naciones Unidas, 1997: 2, párr. 3):

- El art. 27.1 CADH sugiere explícitamente este factor temporal, aunque focalizado en la continuidad temporal de las medidas excepcionales adoptadas, al señalar que deben serlo "por el tiempo estrictamente limitado a las exigencias de la situación».

- El Comité de Derechos Humanos, haciéndose eco en 1981 de los comentados recelos ${ }^{22}$, subrayó implícitamente la naturaleza temporal de la amenaza excepcional (Oraá Oraá, 1992: 21-22), señalando que «las medidas adoptadas de conformidad con el art. 4 [del PIDCP] son de carácter excepcional y temporal» (Comité de Derechos Humanos, 1981: 1, párr. 3).

20 A. and Others v. the United Kingdom [GC], no. 3455/05, párr. 173, ECHR 2009.

21 Ibid., párr. 180.

22 Reiterados en su Observación General Núm. 29 (Comité de Derechos Humanos, 2001: 1, párr. 2). 
Coinciden ambas cláusulas derogatorias en señalar las expectativas tendenciales de temporalidad de la amenaza excepcional, en tanto su desaparición determinará el fin de la legítima habilitación para adoptar medidas excepcionales.

El TEDH no suscribe exactamente esa tesis interpretativa, manteniendo que del art. 15.1 del CEDH no se desprende el requisito de que la amenaza excepcional sea per se temporal. No obstante, la apreciación de la proporcionalidad de las medidas excepcionales se vincula a la duración de la situación ${ }^{23}$ : estas deben revisarse para calibrar su adecuación a la situación e irse atenuando en función de la evolución de la excepcionalidad de la crisis. La temporalidad es fruto, en consecuencia, de la progresiva desaparición de la amenaza excepcional y de la máxima de que las medidas excepcionales no deben aplicarse una vez superada la crisis. Se pisa más el terreno de la provisionalidad y dosificación decrecientes de las medidas excepcionales que el de su temporalidad, siendo más referencial la evolución fáctica que el factor temporal. Este planteamiento concuerda con la práctica del TEDH, proclive a no revisar sistemáticamente en sucesivas sentencias la continuidad o no de una amenaza excepcional ante una prolongada coyuntura de violencia política o terrorista - como sucediera en los supuestos de Irlanda del Norte y Kurdistán-.

\section{LA APLICABILIDAD O NO DEL ARTÍCULO 15 CEDH A LA CRISIS SANITARIA OCASIONADA POR LA COVID-19}

Un triple origen fáctico puede servir para clasificar las situaciones excepcionales (Oraá Oraá, 1992: 31):

- Crisis políticas de diferente naturaleza e intensidad: conflictos armados internacionales o internos; disturbios internos; graves amenazas para el orden público o actos de subversión. Las crisis de naturaleza política que no son calificables de conflicto armado confluyen genéricamente en la noción de disturbios y tensiones internas, en la que existe una grave «amenaza a la seguridad del Estado, al orden público, a la vigencia de la Constitución y de las instituciones democráticas, existencia de actos de violencia, subversión o terrorismo, vandalismo, ataque o amenaza de ataque exterior, motines o rebeliones internas, intento de golpe de Estado, asesinato de miembros del gobierno, etc.» (Naciones Unidas, 1997: 9 y 11, párrs. 28 y 36).

23 A. and Others v. the United Kingdom [GC], no. 3455/05, párr. 178, ECHR 2009. 
- Catástrofes públicas o naturales. Se alude en esta tipología a supuestos de fuerza mayor, constituidos por catástrofes o sucesos imprevistos causados por fuerzas de la naturaleza o por la mano del hombre, por acción o inacción, pudiendo:

a. Originar modificaciones intensivas del medio natural y humano, debido a inundaciones, terremotos, maremotos, ciclones, huracanes, incendios u otros fenómenos como una epidemia, pero también por accidentes nucleares o químicos; pueden provocar consecuencialmente crisis sanitarias o ambientales, más o menos intensas y duraderas.

b. Provocar daños y/o minoraciones en bienes públicos y privados.

c. Poner en riesgo la salud y la vida humanas.

d. Interrumpir el funcionamiento normal de las instituciones públicas y de la vida social, o generar dinámicas sociales que reviertan en crisis políticas.

La existencia y expansión de una epidemia podría pensarse como un supuesto de hecho potencialmente admisible (Negri, 2018: 288), aunque los Principios de Siracusa planteen a priori que una grave amenaza a la salud pública es abordable mediante limitaciones ordinarias, sin que nada se diga en ellos sobre aquellas cuyo grado de gravedad pueda resultar excepcional (Principio 15).

- Crisis económicas. Aunque los Principios de Siracusa son categóricos — «Las dificultades económicas por sí solas no pueden justificar las medidas de derogación» (Principio 41)—, la utilización de poderes excepcionales para abordarlas cuenta con precedentes (Scheuerman, 1999-2000). La práctica internacional revela cómo una crisis económica genera una amenaza excepcional más habitualmente como detonante de una crisis política excepcional (causa mediata), que como causal directo (causa inmediata) ${ }^{24}$. La razonabilidad de este argumento subraya que las crisis económicas acostumbran a producirse por una acumulación de desequilibrios no puntuales que afectan a diversos indicadores, y, que, por tanto, adquieren objetivamente un carácter más estructural que coyuntural. No puede, empero, descartarse que un acontecimiento, episódico o incidental, como "the collapse of a bank; a foreign exchange crisis;

24 Uno de los pocos ejemplos de estado de emergencia económica es el nicaragüense: "A state of economic emergency is hereby decreed in view of the adverse conditions caused by the rise in international oil prices and in view of the necessity of ensuring economic stability in the country and external cooperation flows» (United Nations, 2005: 3). 
or a breakdown in the functioning of essential domestic industries or services» (Law Commission, 2011: párr. 10.7), atendiendo a su gravedad, justifique la invocación de la cláusula derogatoria.

La práctica de los nueve Estados partes del CEDH que antes de 2020 notificaron la existencia de una amenaza excepcional, en su territorio $\mathrm{u}$ otro dependiente de su jurisdicción, refleja la prevalencia de diversas tipologías de crisis políticas (Council of Europe, 2020b): 1) el caos social e institucional causado por una crisis política y financiera que avivó el riesgo de conflicto armado interno (Albania / 1997); 2) la amenaza grave al orden constitucional debido a las protestas por un presunto fraude electoral (Armenia / 2008), por hechos de corrupción (Georgia / 2007) o por violencia política (Turquía /1970-73); 3) el triunfo (Grecia / 1967 y Turquía / 1960 y 1980) o el fracaso (Turquía / 2016) de un golpe de Estado; 4) la existencia de tensiones y disturbios en territorios no metropolitanos (el Reino Unido y Francia); 5) la extensión de la violencia política y la actividad terrorista en Irlanda del Norte (Irlanda y el Reino Unido); 6) los enfrentamientos armados/violencia terrorista en el sudeste de Turquía (Turquía); 7) la existencia de una amenaza terrorista (Reino Unido / 2001 y Francia / 2015); o 8) la falta de control efectivo sobre el Este del país y Crimea tras la «armed aggression» (Council of Europe, 2020b) de la Federación Rusa (Ucrania / 2015).

La jurisprudencia del TEDH demuestra que generalmente los argumentos estatales para justificar la existencia de una amenaza excepcional son aceptados. La excepción es la del caso griego ${ }^{25}$, ya que la Comisión Europea, pese al amplio margen de apreciación estatal, advirtió de la escasa credibilidad de los datos y pruebas presentadas por el gobierno heleno para justificar la presencia de una amenaza excepcional, subrayándose las mentiras que «have been and continue to be met ${ }^{26}$. En el último de los casos examinados, relativo a la represión del golpe de Estado fallido de 15 de julio 2016 en Turquía, el TEDH compartió la opinión del Tribunal Constitucional turco, quizá de modo excesivamente acrítico y deferencial (Mariniello, 2019: 58), de que «the attempted military coup had posed a severe threat to the life and existence of the nation [siempre dentro del amplio margen de apreciación otorgado al Estados parte] $\aleph^{27}$.

25 The Greek Case (Denmark, Norway, Sweden and The Netherlands v. Greece), Commission Report of 5 November 1969. Yearbook of the European Convention on Human Rights, 1969 (12bis), p. 75, párr. 125.

26 Ibid., p. 70, párr. 114.

27 Şahin Alpay v. Turkey, no. 16538/17, párr. 77, 20 March 2018. 
Hasta 2020, solo Georgia había notificado el 2 de marzo 2006, conforme al art. 15.3 CEDH, la adopción de un estado de emergencia por motivos de salud pública (Decreto Presidencial n. ${ }^{\circ} 173$, de 26 de febrero 2006), con el fin de "preventing further spread throughout Georgia of $\mathrm{H} 5 \mathrm{~N} 1$ virus (bird flu) [gripe aviar] that has been recently detected in the district [Khelvachauri] in question» — abrogado por Decreto Presidencial n. ${ }^{\circ} 199$, de 15 de marzo 2006- (Council of Europe, 2020b); la derogación afectaba al derecho a la propiedad (art. 1 Protocolo adicional primero) y a la libertad de circulación (art. 2 Protocolo núm. 4).

Este caso suscita el interrogante sobre en qué medida una crisis sanitaria puede ser considerada una amenaza excepcional. Previamente al mínimo análisis fáctico, cabe considerar dos premisas teleológicas: 1) en períodos de aplicación ordinaria del CEDH y de sus protocolos, la salud pública puede ser un motivo para restringir el ejercicio de los derechos y libertades reconocidos que Georgia derogó; y 2) la crisis sanitaria debe de ser de tal calibre que precise de medidas restrictivas que «superen las limitaciones autorizadas en períodos ordinarios» (Naciones Unidas, 1997: 33, párr. 122).

La valoración de la situación pasa inicialmente por tener presente que la gripe aviar, desde 2003, se había "propagado de Asia a Europa y África», con brotes con «millones de casos de infección de estos animales, varios cientos de casos humanos y la muerte de numerosas personas» (OMS, 2018). Es probable que la situación existente entonces no fuese comparable con la actual pandemia de la COVID-19; de hecho, la decisión georgiana se vinculó a un brote que afectaba a once cisnes (Government of Georgia, 2006). Sin embargo, se habían confirmado en el mundo 117 casos en humanos (98 fallecidos) —algunos en Turquía y Azerbaiyán, países vecinos de Georgia—, mientras se extendía entre animales de nueve Estados de la Unión Europea (Sistema de Vigilancia de la Gripe en España, 2006). La acumulación y extensión de los brotes no dejaba de constituir un riesgo, más o menos inminente, de pandemia; ante lo cual la OMS entendió, en 2005 (OMS, 2005: 1). que debían adoptarse medidas para «mitigar sus repercusiones [proponiéndose medidas «escalonadas»] cuando empiece a extenderse a nivel internacional». No parece descabellado pensar que si en 2005 hubiese sido aplicable el art. 1 del Reglamento Sanitario Internacional (2005), una mayor propagación del virus podía haber comportado considerarla como una Emergencia de Salud Pública de Importancia Internacional (ESPII) ${ }^{28}$, es decir, un evento extraordi-

28 Entró en vigor el 15 de julio de 2007 (por lo que no era aplicable en época de la crisis sanitaria en Georgia); respecto a la COVID-19, la ESPII fue declarada por el Comité de Emergencias de la OMS el 30 de enero de 2020. 
nario constitutivo de «un riesgo para la salud pública de otros Estados a causa de la propagación internacional de una enfermedad» que pudiera "exigir una respuesta internacional coordinada» - lo que sí sucedió con la gripe porcina (H1N1) por decisión del Comité de Emergencias de la OMS, de 27 abril 2009 (OMS, 2009)—.

Cuatro vectores deben apreciarse, principalmente, para ponderar la excepcionalidad de la amenaza existente en Georgia en 2006 desde la perspectiva del art. $15 \mathrm{CEDH}$.

Primero, la situación en Georgia se vinculaba a un riesgo global, más o menos grave, para la salud pública; ciertamente, la relativa importancia del foco infeccioso podría cuestionar la justificación gubernamental de la emergencia excepcional, pero es verdad que se trataba de una enfermedad vírica transmisible al ser humano — como había sucedido en países vecinos-.

Segundo, el seguimiento y la preocupación de la OMS respecto a la extensión de una enfermedad con evidente riesgo pandémico era un indicio de peso para medir la gravedad de la crisis sanitaria, sin perjuicio de no excluir la excepcionalidad sanitaria de un brote epidémico local y aislado de otros focos o de otras tipologías de crisis sanitaria.

Tercero, conectando con la sentencia del TEDH en el asunto A. y otros contra el Reino Unido, era esperable que un Estado - mediante medidas de contención y preventivas - afrontase lo antes posible los riesgos de salud emergentes, sin esperar a que debido a su potencialidad se agravase notoriamente la situación sanitaria para calificarla de modo definitivo como excepcional.

Y, cuarto, que el riesgo calificable de excepcional precisaba de decisiones y medidas sanitarias que fueran más allá de la gestión ordinaria de la salud pública, invadiendo esferas de la libertad, la privacidad y/o la propiedad de los individuos que, habitualmente, no soportan la intromisión de los poderes públicos para garantizar los objetivos de salud pública.

Todo ello parece implicar que no hay datos que cuestionen categóricamente la calificación georgiana de la crisis de salud pública como una amenaza excepcional conforme al art. $15 \mathrm{CEDH}$ : 1) una crisis sanitaria puede resultar excepcional, aun cuando no afecte directa e inicialmente al conjunto de la población, sino solo a una parte de la misma por su asentamiento territorial en un área donde se concentra el riesgo sanitario; y 2) los efectos, reales o potenciales, sobre la salud y la vida de la comunidad organizada en su conjunto pueden ser muy graves. No son datos menores, pero sí complementarios, la no constancia de ninguna demanda contra Georgia ante el TEDH por estos hechos, o que el Comité de Derechos Humanos no entrase en este asunto al examinar el informe periódico de 
Georgia en que se aludía a las consecuencias del estado de emergencia notificado de modo paralelo al Secretario General de las Naciones Unidas conforme al art. 4.3 PIDCP (Comité de Derechos Humanos, 2007: 1-7).

La traslación a la actual crisis sanitaria de estos presupuestos de análisis perfila una doble idea para ponderar la potencial excepcionalidad de la amenaza: 1) la fundamentación situacional se predica del alcance del riesgo para la salud pública, presente o inminente, que un Estado parte afronta por la COVID-19; y 2) es perceptible la contextualización de los riesgos sanitarios en un escenario de propagación transfronteriza global reconocida por la OMS, relativizando incluso el peso del nivel de afección actual de la pandemia, ante la necesidad no solo de mitigar los efectos de la propagación de la enfermedad, sino de adoptar medidas preventivas para contener su progresión dentro del Estado.

No parece fuera de lugar afirmar que, objetivamente, la situación de hecho existente en España el 14 de marzo de 2020 — no se entrará a discutir si con anterioridad las circunstancias podían ya tildarse de excepcionales ni desde qué momento- alcanzaba un nivel de gravedad suficiente como para llegar a ser calificada como una amenaza excepcional (sanitaria) en el sentido del art. 15 CEDH. Tampoco es extraño que en el Reino Unido un tribunal señalase que la expansión de la COVID-19 «establishes a solid foundation upon which a derogation becomes not merely justified but essential» ${ }^{29}$

Los argumentos, acordes con la interpretación del art. 15, pueden ser los siguientes:

- Es una situación de crisis sanitaria actual o inminente de naturaleza excepcional: aunque dependa del nivel de expansión de la infección de la COVID-19 entre la población estatal, nada impide interpretar que el riesgo de propagación masiva en territorio del Estado parte, en un contexto pandémico, es un peligro excepcional e inminente.

- Afecta al conjunto de la población, directa o indirectamente, a tenor de la tipología del peligro: una enfermedad infecciosa declarada pandémica. Aunque el nivel de contagio puede estar territorialmente acotado, la focalización territorial —que podría implicar circunscribir incluso las medidas previstas a áreas específicas - no hace disminuir la gravedad del peligro para el conjunto de la sociedad, debido a que la contención territorial del virus es precisa para evitar su expansión interna.

29 [2020] EWCOP 17, Case No: 1352489T, 23 March 2020, párr. 27. 
- Es una amenaza para la vida organizada de la nación (comunidad), porque no solo tiene efectos institucionales —afectando al normal funcionamiento de los poderes del Estado y/o alterando la prestación de servicios públicos como el sistema sanitario-, sino socioeconómicos; una crisis de salud pública de esta envergadura tensiona gravemente tanto el ejercicio del poder público como la más o menos equilibrada normalidad de la vida social.

- La excepcionalidad se refleja en que las restricciones al ejercicio de los derechos y libertades admitidas por el CEDH y sus protocolos en períodos de normalidad del funcionamiento institucional y de la vida social pueden resultar insuficientes e inadecuadas. Así, por ejemplo, decisiones como el confinamiento generalizado de la población, que afectan temporalmente a la libertad y/o a la libre circulación de las personas, pueden suponer una alteración anormal de difícil incardinación en los parámetros jurídicos y prácticos de la gestión de la salud pública en períodos de funcionamiento ordinario del sistema de salud.

La propia redacción del RD 463/2020, como se ha comentado (véase también el epígrafe III,3), presenta un lenguaje próximo a los parámetros interpretativos del art. $15 \mathrm{CEDH}$, máxime si se examinan las cifras de personas infectadas o fallecidas a 13 de marzo 2020, identificando un problema de salud pública que, de no atajarse, podría adquirir unas enormes proporciones. La argumentación del RD 463/2020 coincide, generalmente, con la posición de aquellos Estados partes que sí han decidido invocar la cláusula derogatoria por entender que se encontraban en una situación excepcional a causa de la COVID-19. Este extremo es perceptible al examinar las motivaciones y las medidas comunicadas al Consejo de Europa, sin perjuicio de que el lenguaje sea más comedido que el del RD 463/2020 respecto a la explicitación de la gravedad de la amenaza, pues suelen omitir los términos excepcional o extraordinaria.

El Gobierno de Armenia ${ }^{30}$, por ejemplo, alude en su carta de 19 de marzo 2020 a una actuación «in response to the global outbreak and spread of COVID-19 virus», mientras que, en la Decisión 298-N, de 16 de marzo 2020, por la que se decreta el estado de emergencia, se subraya: 1) el hecho de que el director general de la OMS el 11 de marzo 2020 calificase de pandemia la expansión de la COVID-19; y 2) que, aunque focalizada en la ciudad de

30 Note Verbale. Permanent Representation of the Republic of Armenia to the Council of Europe. J9015C, 20 March 2020 (Council of Europe, 2020a). 
Vagharshapat, el país se encontraba en «an emergency situation resulting from the epidemic» que suponía «a threat to the life and health of the population and may result in the disruption of the normal living conditions of persons».

Armenia incide en cuatro vectores para justificar la excepcionalidad de la amenaza: 1) la existencia de focos — aparentemente limitados- de COVID-19 en su territorio; 2) su contextualización en el riesgo global que comporta una pandemia con las especificidades de la COVID-19; 3) la convergencia de los otros dos vectores en la presencia de un potencial peligro de expansión bajo su jurisdicción de la COVID-19 y de una amenaza inminente para la vida y la salud de las personas ${ }^{31}$; y 4) la lógica de la voluntad de actuar desde la percepción de la temporalidad de la amenaza excepcional. Estos vectores aconsejaban, según Armenia, adoptar inmediatamente medidas invasivas de derechos y libertades reconocidos en el CEDH y sus protocolos, para prevenir y contener la expansión de la enfermedad. Todo ello no deja de evocar la dicotomía dialéctica que separa normalidad y emergencia, concerniendo esta última a situaciones de urgencia, repentina y/o de intervención rápida (Gross y Oren, 2006: 172).

Las particularidades de la situación sanitaria de cada Estado y/o de su normativa interna para dar cobertura legal a la toma de decisiones — sea mayoritariamente la declaración del estado de emergencia o bien la de desastre natural ${ }^{32}$ - no impiden ver reproducidos generalmente los vectores descritos ${ }^{33}$. Georgia es el exponente de otro razonamiento complementario que completa la construcción argumental modelo: la insuficiencia del arsenal ordinario de medidas sanitarias adoptadas previamente para luchar contra la COVID-1934; si en Georgia se detectó el primer caso el 26 de febrero 2020, al decretarse el 21 de marzo de 2020 el estado de emergencia se consideró que el incre-

31 La mayoría de las notificaciones, a diferencia de esta, aluden formalmente a una amenaza inminente para la salud pública.

32 Note Verbale. Permanent Representation of the Republic of Albania to the Council of Europe. J9020C, 1 April 2020 (Council of Europe, 2020a). En el caso de San Marino, solo se alude conforme a su acerbo constitucional a la habilitación para la adopción de medidas urgentes y necesarias para reducir y gestionar la expansión del virus (Note Verbale. Permanent Representation of the Republic of San Marino. JJ9026C, 14 April 2020 [Council of Europe 2020a]).

33 En el caso rumano, el Decreto no. 195, de 16 de marzo 2020, por el que se establece el estado de emergencia, alude a la práctica seguida por otros Estados ante la crisis sanitaria (Permanent Representation of the Republic of Romania to the Council of Europe. JJ9014C, 18 March 2020 [Council of Europe, 2020a]).

34 Nada indica que los países que no hayan recurrido al art. $15 \mathrm{CEDH}$ se abstuviesen de tomar previamente medidas relacionadas con la gestión de la salud pública. 
mento del número de personas infectadas aconsejaba adoptar «[additional and] exceptional measures to ensure safety and protection of public health ${ }^{35}$.

A pesar de admitir que difícilmente el TEDH «refuserait la validité des dérogations visant à contenir l'épidémie de Covid-19" — considerando tanto el número de fallecimientos ya causados como el alcance de su propagación-, es perceptible cómo se cuestiona la oportunidad de la casi simultánea invocación de la cláusula derogatoria por diez Estados partes (Gudzenko, 2020: 3-4). Desde la portavocía del Consejo de Europa —Daniel Holtgen-, se ha señalado en esta dirección que «most measures taken to prevent the spread of the coronavirus are already covered by the Convention", por lo que desde la organización internacional no se estaba «actively encouraging or even obliging member states to make such notification» (Makszimov, 2020). Sin embargo, desde el propio Consejo de Europa, se admite, antes de subrayar que dependerá de la naturaleza y extensión de las medidas adoptadas respecto a los derechos y libertades reconocidos por el CEDH y sus protocolos si es preciso que un Estado parte invoque el art. $15 \mathrm{CEDH}$, que: «It is also understood that the regular functioning of society cannot be maintained, particularly in the light of the main protective measure required to combat the virus, namely confinement» (Council of Europe, 2020c: 2). Todo lo cual, más allá de no desmontar radicalmente el argumento sobre la excepcionalidad situacional, sitúa el asunto en el ámbito de la potencial excepcionalidad (o no) de las medidas adoptadas.

\section{LAS MEDIDAS ADOPTADAS PARA COMBATIR LA CRISIS SANITARIA Y SU COMPATIBILIDAD CON EL CEDH Y SUS PROTOCOLOS}

Los Estados partes, para afrontar la COVID-19, han optado por dos vías jurídicas distintas para legitimar medidas que repercuten en el goce y disfrute de los derechos y libertades reconocidos en el CEDH y sus protocolos: las técnicas jurídicas de restricción ordinaria de los derechos y libertades versus la cláusula derogatoria. Esto hace preciso verificar las consecuencias jurídicas de esta divergencia respecto a la aplicabilidad del CEDH y sus protocolos frente a la crisis de la COVID-19. Particularmente porque, si la crisis sanitaria puede ser una amenaza excepcional, es factible que las medidas necesarias para abordarla también lo sean, en contraposición a las ordinarias dirigidas a abordar un riesgo grave pero ordinario.

35 Note Verbale. Permanent Representation of the Republic of Albania to the Council of Europe. JJ9018C, 21 March 2020 (Council of Europe, 2020a). 
Se analizarán, en tres apartados, los siguientes aspectos: 1) los efectos jurídicos del cumplimiento de la obligación de notificación conforme al art. 15.3 CEDH; 2) la tipología de medidas adoptadas por los Estados partes frente a la COVID-19 desde el prisma del CEDH y sus protocolos; y 3) la especificidad de la práctica española respecto a la COVID-19.

\section{LOS EFECTOS JURÍDICOS DEL CUMPLIMIENTO DE LA OBLIGACIÓN DE NOTIFICACIÓN CONFORME AL ARTÍCULO 15.3 CEDH}

Junto a la preservación de los intereses de los otros Estados partes (legitimación activa para presentar una demanda interestatal) ${ }^{36}$ o del adecuado ejercicio de sus competencias por el $\mathrm{TEDH}^{37}$, un tercer argumento justificativo de las exigencias del art. 15.3 $\mathrm{CEDH}$ es garantizar el conocimiento por los individuos de las medidas que afectan a sus derechos y libertades (Svensson-McCarthy, 1998: 704).

Esta condición formal de la invocación de la cláusula derogatoria (Sudre 2015, 226) — pero, eso sí, una formalidad sustancial para prevalerse de la misma (Gonzalez 2007, 95) — insta a informar plena e inmediatamente tanto "de las medidas tomadas y de los motivos que las han inspirado» ${ }^{38}$, como de la "fecha en que esas medidas hayan dejado de estar en vigor». En la medida en que es requerida una "permanent review of the need for emergency measures ${ }^{39}$, la remisión de información adquiere un carácter obligacional dinámico y continuado.

La notificación, en la práctica, suele transmitirse a través de una nota verbal de la representación permanente del Estado parte ante el Consejo de Europa, que incorpora una carta del Gobierno, junto a "copies of the legal texts under which the emergency measures will be taken, with an explanation of their purpose» (European Court of Human Rights, 2019: 11, párr. 35).

36 Greece against United Kingdom, Applications Nos. 176/56, Commission Report of 26 September 1958, Vol. 1, p. 168; por entonces, para presentar una denuncia ante la Comisión Europea de Derechos Humanos (art. 24 CEDH originario).

$37 \mathrm{El} \mathrm{TEDH}$ «must give appropriate weight to such relevant factors as the nature of the rights affected by the derogation and the circumstances leading to, and the duration of, the emergency situation" (Aksoy v. Turkey, 18 December 1996, párr. 68, Reports of Judgments and Decisions 1996-VI).

38 Por ejemplo, no se consideró significativo un retraso de doce días respecto a la entrada en vigor de las medidas excepcionales [Lawless v. Ireland (no. 3), 1 July 1961, párr. 47, Series A no. 3].

39 Brannigan and McBride v. the United Kingdom, 26 May 1993, párr. 54, Series A no. 258-B. 
Es remarcable la ausencia de mención tanto en el art. $15 \mathrm{CEDH}$ (Sottiaux, 2018: 1074) como en la CSE/CSE revisada a la necesidad de que conste la proclamación oficial del recurso a los poderes excepcionales — se presume que acorde con la configuración jurídica interna de su ejercicioEsta diferencia del art. $15 \mathrm{CEDH}$ respecto a los arts. 4 PIDCP, $27 \mathrm{CADH}$ y 4 Carta Árabe de Derechos Humanos podría insinuar que el CEDH prescinde del principio de proclamación.

La práctica relativa al art. 15.3 $\mathrm{CEDH}$ parece inclinarse por exigir al Estado parte un acto jurídico identificable con la proclamación oficial; al evaluar la aplicabilidad de la cláusula derogatoria en el norte de Chipre tras la invasión turca, la Comisión Europea señaló que «in any case, Art. 15 $[\mathrm{CEDH}]$ requires some formal and public act of derogation, such as a declaration of martial law or state of emergency, and that, where no such act has been proclaimed by the High Contracting Party concerned $»^{40}$.

Esta exigencia parece fundamentarse, no tanto en la naturaleza de la cláusula derogatoria y de lo esperable de un Estado democrático, sino en una de «las restantes obligaciones que dimanan del derecho internacional»" (art. 15.1 CEDH) y, en concreto, de lo dispuesto en el art. 4.3 PIDCP. Esta contribución a una óptica obligacional holística ante situaciones excepcionales (El Zeidy, 2003: 293) requiere que los Estados partes del CEDH lo sean a su vez del PIDCP, ante la dificultad de justificar su reconocimiento por el Derecho internacional general (véase nota 8).

Los requisitos que debe reunir este acto formal y público de derogación son interpretados de forma flexible y casuística, partiendo de que, como señala el TEDH, no le corresponde «to seek to define authoritatively the meaning of the terms 'officially proclaimed' in Article 4 of the Covenant [PIDCP]» ${ }^{42}$. Su exigencia, empero, es indicativa de que la potencial laxitud en el ámbito del ejercicio de poderes excepcionales tiene como límite el respeto al principio de legalidad y a la preexistencia de las normas jurídicas que contemplen esta facultad (Principio 43 de los Principios de Siracusa).

40 Cyprus against Turkey, Applications Nos. 6780/76 and 6950/75, Commission Report of 10 July 1976, p. 162, párr. 527; Cyprus against Turkey, Application No. 8007/77, Commission Report of 4 October 1983, p. 17, párr. 67.

41 Brannigan and McBride v. the United Kingdom, 26 May 1993, pars. 71-73, Series A no. 258-B.

42 Ibid., párr. 73. 
Las consecuencias jurídicas de la no proclamación oficial, según la Comisión Europea ${ }^{43}$, determinan que el art. $15 \mathrm{CEDH}$ "cannot apply», en el caso particular, "to measures taken by Turkey with regard to persons or property in the north of Cyprus». En definitiva, el Estado parte no puede ni invocar el art. 15 CEDH (Sudre, 2015: 226) ni justificar su comportamiento y sus decisiones en los términos previstos en la cláusula derogatoria.

Ocho de los diez Estados partes que han notificado su recurso al art. $15 \mathrm{CEDH}$ por causa de la COVID-19 lo han hecho tras haber formalmente proclamado el estado de emergencia o de catástrofe a tenor de su texto constitucional, mientras Letonia ${ }^{44}$ señaló actuar bajo su legislación de excepción y San Marino ${ }^{45}$ conforme a los poderes para legislar por decreto del Congresso di Stato en supuestos de urgencia y necesidad.

Hay que examinar también los efectos jurídicos de la no notificación cuando el Estado parte podría estar en disposición de invocar la cláusula derogatoria, debido a la aplicación de normas jurídicas propias de situaciones excepcionales. Más allá de que la Comisión Europea orillase decidir sobre si el incumplimiento de los requerimientos del art. $15 \mathrm{CEDH}$ «attract the sanction of nullity or some other sanction ${ }^{46}$, la falta de notificación supone incumplir el párr. 3 del art. $15 \mathrm{CEDH}$, por lo que parece lógico jurídicamente entender que no cumplimentar esta condición formal comporta que el Estado Parte "will lose the right of derogation»(Oraá Oraá, 1992: 70). Esta consecuencia jurídica implicaría enjuiciar la conducta estatal conforme a las facultades ordinarias de restricción previstas en el CEDH y sus protocolos, es decir, llevar a cabo un control «normal» de las potenciales violaciones planteadas (Gonzalez 2007, 96).

Es notorio que tanto la Comisión Europea como el TEDH «have consistently avoided deciding whether notification is, in this way, a condition precedent for valid derogation» (Holcroft-Emmess 2020, 4). No obstante, el TEDH admitió la presencia de un contexto de insurgencia suficientemente grave en Chechenia como para constituir de facto una situación excepcional que demandaba «exceptional measures on behalf of the State in order to regain

43 Cyprus against Turkey, Applications Nos. 6780/76 and 6950/75, Commission Report of 10 July 1976, p. 162, párr. 528.

44 Note Verbale. Permanent Representation of the Republic of Latvia to the Council of Europe. JJ9012C, 16 March 2020 (Council of Europe, 2020a).

45 Art. 2.2 b) de la Legge Constituzionale, 15 dicembre 2005, n.183 (Note Verbale. Permanent Representation of the Republic of San Marino. JJ9026C, 14 April 2020 [Council of Europe, 2020a]).

46 Cyprus against Turkey, Applications Nos. 6780/76 and 6950/75, Commission Report of 10 July 1976, p. 161, párr. 526. 
control over the Republic and to suppress the illegal armed insurgency» ${ }^{47}$. La falta de proclamación oficial del estado de emergencia y la no invocación formal del art. $15 \mathrm{CEDH}^{48}$ supusieron la aplicación al Estado parte del art. 2.2 $\mathrm{CEDH}$ (excepciones en que cabe privar del derecho a la vida) sin la potencialidad añadida del art. $15.2 \mathrm{CEDH}^{49}$.

Parece más difícil determinar los efectos jurídicos de la inadecuación del contenido de la notificación inicial y de sus potenciales actualizaciones, si bien puede señalarse que:

- Es perceptible la relatividad de la profundización jurisprudencial del $\mathrm{TEDH}^{50}$, pues «does not seem to give weight to claims concerning the vague nature of the derogation notification to the Council of Europe» (Mariniello, 2019: 63).

- El TEDH ha tendido a asumir la conformidad de las notificaciones, a poco que ofreciesen una mínima información: por ejemplo, aunque no se mencionaran en la notificación turca qué derechos y libertades del $\mathrm{CEDH}$ y sus protocolos estaban afectados, la falta de cuestionamiento por las partes del contenido de la notificación le sirvió para afirmar que estaba "prepared to accept that this formal requirement has been satisfied ${ }^{51}$. En su reciente notificación, téngase presente que ni Rumania, ni Armenia ni Serbia «did not mention expressly [...] the articles affected [del CEDH] by their derogation" (Zghibarta, 2020: 2).

- Aunque sea razonable decir que el asunto no puede resolverse radicalmente en favor o no de la nulidad del ejercicio de los poderes excepcionales (Oraá Oraá, 1992: 70), el TEDH la ha abordado como una condición del ejercicio del derecho excepcional de derogación ${ }^{52}$; es decir, como un requisito teóricamente determinante de la validez del recurso al art. 15 $\mathrm{CEDH}$. Ahora bien, al decidir sobre la aplicabilidad de una derogación, parece que el problema de fondo subyacente en la deficiencia formal fuera el tema esencial: por ejemplo, la inaplicabilidad de la derogación a parte del territorio estatal porque esa área no fue «explicitly named in the

47 Isayeva and Others $v$. Russia, nos. 57947/00 and 2 others, párrs. 162 y 168, 24 February 2005.

48 Ibid., párr. 125; en esta misma dirección: Khachiev and Akä̈eva v. Russia, nos. 57942/00 and 57945/00, párr. 97, 6 July 2005.

49 Sobre la declaración del estado de alarma a este respecto, véase epígrafe III.3.

50 Aksoy v. Turkey, 18 December 1996, párr. 86, Reports of Judgments and Decisions 1996VI.

51 Şahin Alpay v. Turkey, no. 16538/17, párr. 73, 20 March 2018.

52 Ibid., párr. 72. 
notice of derogation $»^{53}$. Es patente, empero, cómo la inadecuada notificación impide formalmente como proyección del problema de fondo el ejercicio de los poderes excepcionales conforme al art. $15 \mathrm{CEDH}$ en el territorio no mencionado.

- Salvando las distancias técnico-jurídicas entre ambas instituciones, hay que fijarse en el régimen jurídico para la formulación de reservas por los Estados previsto en el art. $57 \mathrm{CEDH}$ (antiguo art. 64). El TEDH ha apreciado la invalidez de las reservas no conformes con este régimen jurídico ${ }^{54}$, enjuiciando el comportamiento estatal como si no hubiese sido formulada la reserva y aplicando, por consiguiente, las disposiciones del CEDH sin tener presente el contenido de esta (Svensson-McCarthy, 1998: 715-716).

\section{LA TIPOLOGÍA DE MEDIDAS ADOPTADAS POR LOS ESTADOS PARTES FRENTE A LA COVID-19}

Si son significativas respecto a las condiciones formales del art. 15.3 $\mathrm{CEDH}$ las «inherent limitations [apreciación más ajustada que aludir a una 'total inability' (Hartman 1981, 22)] to tackle the magnitude of the problems associated with derogations» (Kushtrim and Salomon, 2019: 23) del mecanismo de garantía colectiva del $\mathrm{CEDH}$, lo son más frente a los aspectos de fondo relativos a la cláusula derogatoria, porque la actividad de supervisión puede que solo sea ejercitada previa presentación de demandas interestatales $\mathrm{o}$ individuales ${ }^{55}$. Esto resalta la ausencia de una fórmula específica de revisión de las derogaciones - opción sugerida durante los trabajos preparatorios del CEDH y del PIDCP (Council of Europe, 1956: 17) —. De ahí la solicitud de la Asamblea Parlamentaria del Consejo de Europa para que el secretario general y depositario del CEDH mantenga una posición más proactiva respecto a las derogaciones notificadas (apdo. 20 de la Resolution 2209 (2018), State of

53 Sakık and Others v. Turkey, 26 November 1997, párr. 39, Reports of Judgments and Decisions 1997-VII; también: Abdülsamet Yaman v. Turkey, no. 32446/96, párr. 69, 2 November 2004 y Yurttas v. Turkey, nos. 25143/94 and 27098/95, párr. 58, 27 May 2004.

54 Belilos v. Switzerland, 29 April 1988, párr. 60, Series A no. 132.

55 Estas limitaciones pueden verse mínimamente atenuadas por la competencia atribui$\mathrm{da}$ al secretario general para realizar indagaciones (art. $52 \mathrm{CEDH}$ ) o el posible juego que del Protocolo núm. 16, entrado en vigor el 1 de agosto 2018, para que los órganos jurisdiccionales internos soliciten al TEDH una opinión consultiva relativa a la interpretación y aplicación de los derechos y libertades reconocidos en el ECDH y sus protocolos. 
emergency: proportionality issues concerning derogations under Article 15 of the European Convention on Human Rights, 24 April 2018).

Esta disfunción es más relevante, ante la dualidad de vías convencionales que han articulado la injerencia en los derechos y libertades previstos en el $\mathrm{CEDH}$ y sus protocolos frente a la COVID-19 y la ausencia de precedentes jurisdiccionales sobre hipotéticas amenazas sanitarias excepcionales (Kushtrim and Salomon, 2019:23), porque cuando menos se tardarán 5 o 6 años en que se reflejen en la jurisprudencia del TEDH (Dzehtsiarou, 2020: 1).

Tres ideas resultan básicas para entender la complejidad de la diferenciación entre el hipotético alcance de las medidas restrictivas ordinarias, autorizadas a través de las disposiciones específicas de cada derecho y libertad reconocido, y el de las medidas restrictivas excepcionales (derogatorias), autorizadas por la cláusula derogatoria: 1) pese a que se apoye en la práctica estatal, la delimitación de los términos empleados por el TEDH surge de la «autonomous interpretation of the legal concepts set out» en el CEDH y sus protocolos (Carrillo Salcedo, 2009: 664) —construcción de nociones autónomas-; 2) no es imposible que el Estado parte combine ambas tipologías de medidas para atajar la amenaza excepcional —algunas restricciones ordinarias pueden bastar ante aspectos particulares de la crisis excepcional-; y 3) la distinción tendrá mucho de ejercicio casuístico a partir, sobre todo, del art. $15 \mathrm{CEDH}$. Si puede afirmarse, en general, que son medidas que "would not normally be permisible» (Sottiaux, 2018: 1065), puede comprobarse cómo el art. 15 $\mathrm{CEDH}$ autoriza a los Estados partes a derogar sus obligaciones jurídicas conforme al CEDH y sus protocolos, es decir, a no tener que aplicar sus obligaciones jurídicas respecto a ciertos derechos y libertades durante el período de excepción - «se libérer des obligations relatives aux droits de l'homme» (Sudre, 2015: 226) - . Se le habilita, pues, a «suspender de manera temporal, limitada y controlada» su ejercicio (Casadevall, 2012: 174).

Esta aproximación inicial debe completarse con tres precisiones muy relevantes si se recuerda que la cláusula derogatoria ha sido invocada normalmente ante crisis de naturaleza política: 1) la práctica jurisdiccional se ha concentrado en la prolongación de los períodos de detención preventiva (incluidos internamientos) y los previos a la puesta a disposición judicial (Sottiaux, 2018: 1071); 2) existen derechos y libertades inderogables bajo cualquier circunstancia; y 3) tampoco es plausible derogar totalmente las garantías personales y procesales a quienes están privados de libertad.

Sobre cómo, con estos mimbres, el TEDH examina las medidas derogatorias puede decirse, primero, que ha partido de un tratamiento particularizado de los parámetros de necesidad y de proporcionalidad, ajustado a la especificidad de la amenaza excepcional y a la implícita naturaleza temporal de las medidas: debe darse «appropriate weight to such relevant factors as the 
nature of the rights affected by the derogation and the circumstances leading to, and the duration of, the emergency situation ${ }^{56}$, sin perjuicio de que, en la ponderación de si la derogación es mesurada (Gonzalez, 2007: 99), se otorgue un amplio margen de apreciación.

Segundo, desde el principio ${ }^{57}$ la conformidad de las medidas excepcionales se ha vinculado a su comprensión como último recurso (El Zeidy, 2003: 289) o como una "genuine response to the emergency situation ${ }^{58}$ : «The ordinary legal procedures and other less invasive alternative extraordinary measures were regarded as ineffective» (Svensson-McCarthy, 1998: 618).

Tercero, no es aceptable una medida excepcional de carácter discriminatorio: detener e internar diferenciadamente a extranjeros sospechosos de terrorismo es "disproportionate in that they discriminated unjustifiably between nationals and non-nationals $»^{59}$.

Cuarto, aunque pueda ser desvirtuado por la falta de razonabilidad o desproporción de las medidas derogatorias, no puede infravalorarse el margen de apreciación concedido al Estado parte como presunción favorable respecto a sus argumentos y conductas (Born, Morris y Forest, 2020: 79), ofreciendo «some leeway to the national authorities of the Member States" (Zoethout, 2014: 329).

$\mathrm{Y}$, quinto, pese a que el más que atemperado y complaciente ejercicio jurisdiccional se haya vuelto algo más estricto (Sottiaux, 2018: 1076) - por ejemplo, al evaluar las salvaguardias en situaciones de detención prolongada $^{60}$-, sigue pareciendo necesario que el TEDH ejerza un «more rigorous and principled scrutiny of the derogation» (Mariniello, 2019: 68).

Dejando de lado las medidas socioeconómicas, los Estados partes, hayan invocado o no la cláusula derogatoria, han desplegado un arsenal ingente de medidas que repercuten en una pluralidad de disposiciones del CEDH y sus protocolos.

La imposibilidad de reflejar un análisis exhaustivo demanda realizar una exploración comparativa de las principales coincidencias:

56 A. and Others v. the United Kingdom [GC], no. 3455/05, párr. 173, ECHR 2009.

57 El TEDH afirmó que «in 1957 the application of the ordinary law had proved unable to check the growing danger which threatened the Republic of Ireland» [Lawless $v$. Ireland (no. 3), 1 July 1961, párr. 36, Series A no. 3].

58 Baş v. Turkey, no. 66448/17, párr. 196, 3 March 2020.

59 A. and Others $v$, the United Kingdom [GC], no. 3455/05, párr. 173, ECHR 2009.

60 Por ejemplo, el TEDH admitió que la pérdida de intensidad de la amenaza excepcional provocada por el intento de golpe de Estado en Turquía demandaba mayor rigor al valorar el tiempo pasado por el detenido antes de ser llevado ante el juez (Baş $v$. Turkey, no. 66448/17, pars. 224-230, 3 March 2020). 
- Posibilidad de exigir obligatoriamente determinados trabajos o servicios (art. $4 \mathrm{CEDH}$ ).

- Medidas que afectan al derecho de acceso a los tribunales (por ejemplo, que afectan al funcionamiento del sistema judicial) y/o a las garantías en los procedimientos administrativos sancionadores (art. $6 \mathrm{CEDH}$ ).

- Medidas que afectan al tratamiento de los datos médicos u otros datos personales ${ }^{61}$, prohibición o limitación de visitas hospitalarias, o medidas que limitan relaciones personales y comunicaciones de colectivos como los presos o los militares (art. $8 \mathrm{CEDH}$ ).

- Suspensión o limitación de las actividades en lugares de culto (art. 9 CEDH).

- Prohibiciones o exigencias relativas a la transmisión de información (art. $10 \mathrm{CEDH})^{62}$.

- Prohibiciones o limitaciones de los derechos de reunión y manifestación, incluyendo la prohibición de huelgas o de actividades conjuntas vinculadas al ocio (art. $11 \mathrm{CEDH}$ ).

- Privación o limitación de la disponibilidad de bienes y/o de las actividades económicas vinculadas a los mismos (art. 1 Protocolo adicional primero).

- Suspensión o limitación de actividades escolares (art. 2 Protocolo adicional primero).

- Aplazamiento de la celebración de elecciones (art. 3 Protocolo adicional primero).

- Suspensión o limitación de la libertad de circulación, con determinados niveles de intensidad respecto a sus dimensiones exterior e interior, o la exigencia del aislamiento o confinamiento domiciliario o en centros habilitados según el caso (art. 2 Protocolo núm. 4 y/o art. 5.1 e) $\mathrm{CEDH})^{63}$.

61 Téngase presente, respecto a las aplicaciones de móvil para controlar la evolución de la pandemia la Recomendación (UE) 2020/518 de la Comisión de 8 de abril de 2020 relativa a un conjunto de instrumentos comunes de la Unión para la utilización de la tecnología y los datos a fin de combatir y superar la crisis de la COVID-19, en particular por lo que respecta a las aplicaciones móviles y a la utilización de datos de movilidad anonimizados (DOUE, L 114, de 14 de abril de 2020).

62 Note Verbale. Permanent Representation of the Republic of Armenia to the Council of Europe. J9015C, 20 March 2020, p. 8 (Council of Europe, 2020a).

63 Prevé la "privación de libertad, conforme a derecho, de una persona susceptible de propagar una enfermedad contagiosa, de en enajenado, de un alcohólico, de un toxicómano o de un vagabundo». 
Asimismo, si de los arts. 2, 3 y $8 \mathrm{CEDH}$ se infieren obligaciones positivas que requieren "specific affirmative tasks» (Mowbray, 2004: 2), esto significa específicamente "to take measures to safeguard the health of an individual» (European Court of Human Rights, 2015: 5). Partiendo, eso sí, de que los arts. 2 y $3 \mathrm{CEDH}$ son inderogables, no es imposible que, ante una crisis sanitaria como la de la COVID-19, «acts and omissions of the authorities in the field of health care policy may in certain circumstances ${ }^{64}$ ser insuficientes o inadecuadas. Respecto al art. $2 \mathrm{CEDH}$, esto parece implicar la «obligación de tomar las medidas adecuadas de protección de la vida» (Vaquerizas Pulido, 2020: 9-10), lo que ante la actual pandemia abarca la disponibilidad de herramientas normativas y operacionales adecuadas.

Podría conjeturarse que, si en buena medida, las disposiciones mencionadas pueden encuadrarse en excepciones (por ejemplo, art. $4.3 \mathrm{CEDH}$ ) o cláusulas restrictivas (por ejemplo, art. 11.2 CEDH) susceptibles de justificar jurídicamente la restricción ordinaria del ejercicio de los derechos y libertades reconocidos por causa de una crisis de salud pública, el «deployment of Article 15 [frente al despliegue de restricciones ordinarias] will not make too much difference in the context of the COVID-19", enviando además «an unnecessary message to people that states will start limiting their human rights» (Dzehtsiarou, 2020: 1-2). Se ha querido destacar, como apoyo a la posición que tilda de inoportuno el recurso al art. $15 \mathrm{CEDH}$, la elasticidad de las excepciones y restricciones previstas en el $\mathrm{CEDH}$ y sus protocolos como justificación de lo innecesario del recurso a la cláusula derogatoria (Gudzenko, 2020: 7).

Estos argumentos no parecen del todo irrebatibles, en primer lugar, porque contextualmente el conjunto de medidas adoptadas sugiere un espacio situacional de extrema gravedad (excepcional), aun cuando las restricciones pudieran por separado ajustarse a un marco jurídico ordinario.

En segundo lugar, porque, aunque no hayan invocado el art. $15 \mathrm{CEDH}$, algunos Estados proyectan el lenguaje jurídico de esta disposición al articular sus medidas restrictivas. Así, por ejemplo, la modificación del Código de la Salud Pública francés —Loi n 2020-290 du 23 mars 2020 - introduce el estado de urgencia sanitaria (art. L3131-12) ${ }^{65}$ ante una "catastrophe sanitaire

64 Zdzisław Nitecki v. Poland (dec.), no. 65653/01, 21 March 2002.

65 Francia no ha recurrido al art. 16 de su Constitución que contempla adoptar medidas cuando «les institutions de la République, l'indépendance de la nation, l'intégrité de son territoire ou l'exécution de ses engagements internationaux sont menacées d'une manière grave et immédiate et que le fonctionnement régulier des pouvoirs publics constitutionnels est interrompu». 
mettant en péril, par sa nature et sa gravité, la santé de la population»; tras explicitar las medidas a adoptar en tal caso — que están entre las previamente explicitadas—, el art. L3131-14 se cierra así: «sont [temporal y] strictement proportionnées aux risques sanitaires encourus et appropriées aux circonstances de temps et de lieu».

$\mathrm{Y}$, en tercer lugar, porque la concreción de las medidas restrictivas adoptadas puede objetivamente llegar a desbordar el estricto marco de la interpretación del alcance de las restricciones ordinarias previstas en el CEDH y sus protocolos, pudiendo colegirse que son suficientes porque son restricciones excepcionales (derogaciones).

Un ejemplo cualificado, a partir de la dificultad de fundar ordinariamente en el art. 5.1 e) $\mathrm{CEDH}$ (véase nota 63) o en el art. 2 Protocolo núm. 4 -el TEDH ha indicado que la diferencia «between deprivation and restriction of liberty is one of degree or intensity and not one of nature or substance ${ }^{66}$ - es la determinación de si ciertas medidas de confinamiento obligatorio, aislamiento o cuarentena adoptadas por los Estados partes son excepciones o restricciones ordinarias por motivos de salud pública o si, por el contrario, son susceptibles de ser calificadas como excepcionales en el sentido del art. $15 \mathrm{CEDH}$.

- El TEDH ha considerado como restricción ordinaria desproporcionada, a falta de explorar otras medidas menos severas, el confinamiento obligatorio (prolongado) de una única persona infectada por el virus del VIH, autorizada por un tribunal administrativo sueco, pues la «compulsory isolation of the applicant was not a last resort in order to prevent him from spreading the HIV viru ${ }^{67}$. Debe reflexionarse, adicionalmente, sobre si el art. 5.1(e) «allows for the deprivation of liberty of healthy people to prevent the spread of infectious diseases» (Greene, 2020).

- No parece tan fácilmente encajable como una restricción ordinaria el confinamiento obligatorio para toda la población de manera indiscriminada - no distinguiéndose entre contagiados, sospechosos de estarlo $\mathrm{u}$ otros individuos- . Parece una medida suspensiva general del ejercicio de un derecho o libertad, sometida a excepciones, y, por tanto, de una restricción jurídica y situacionalmente propia más bien de una amenaza excepcional ${ }^{68}$. Las dudas se extienden, asimismo, al confinamiento de

66 De Tommaso v. Italy [GC], no. 43395/09, párr. 80, 23 February 2017.

67 Enhorn v. Sweden, no. 56529/00, párr. 55, ECHR 2005-I.

68 A diferencia, por ejemplo, de una prohibición de entrada en una zona de la una ciudad durante catorce días debido a una emergencia relacionada con el tráfico y 
todas las personas llegadas al país tras la entrada en vigor de las medidas anti-COVID19 (Gudzenko, 2020: 8).

Estos argumentos, según la intensidad de la respuesta estatal, pueden predicarse de otros derechos y libertades restringidos por esta causa. Incluso autores proclives a inscribir la tipología de medidas descritas como restricciones ordinarias vinculadas a la obligación estatal de proteger la vida y la salud admiten que es dudoso que «all the restrictions being imposed require a derogation to remain consistent with the requirements of the Convention but there are others which may need one, particularly if they last for a prolonged period» (McBride, 2020).

Más allá de que la invocación o no del art. $15 \mathrm{CEDH}$ implique una elección política y jurídica del Estado, se ha justificado la adecuación de recurrir al mismo por la multiplicidad y significación de los derechos y libertades concernidos (Costa 2020), o la dificultad de acomodar parte de las medidas estatales a la normalidad restrictiva que implica la opción de no invocar la cláusula restrictiva - destacando, particularmente, aquellas medidas estatales relativas a la privación de libertad y/o de libertad deambulatoria (Greene, 2020)—. Más explícitamente respecto al caso francés, se ha señalado que el estado de urgencia sanitaria suspende de lege y de facto la $\mathrm{CEDH}$ y sus protocolos con la excepción de los derechos no derogables (Sudre, 2020).

Las posiciones, sin un pronunciamiento del TEDH, son divergentes, aunque convergen en admitir que no es imposible que algunas de las medidas adoptadas excedan de los recursos ordinarios de que, a tenor del CEDH y sus protocolos, disponen los Estados partes en situaciones como la descrita.

\section{LA ESPECIFICIDAD DE LA PRÁCTICA ESPAÑOLA RESPECTO A LA COVID-19}

Partiendo de que, como sucede con normativa previa y posterior al mismo se reconozca la excepcional gravedad situacional (Boletín Oficial del Estado, 2020) ${ }^{69}$, la redacción del RD 463/2020 perfila tres consideraciones

consumo de estupefacientes (Landvreugd v. the Netherlands, no. 37331/97, párr. 74, 4 June 2002; Olivieira v. the Netherlands, no. 33129/96, párr. 65, ECHR 2002-IV).

69 «Emergencia de salud pública de importancia internacional» (Preámbulo del Real Decreto-ley 7/2020, de 12 de marzo, por el que se adoptan medidas urgentes para responder al impacto económico del COVID-19 [BOE, núm. 65, 13 de marzo de 2020]). La Orden PCM/205/2020, de 10 de marzo ( $B O E$, núm 61, de 10 de marzo de 2020) y la Orden PCM/216/2020, de 12 de marzo (BOE, núm. 64, de 12 de marzo de 2020) publicaron los Acuerdos del Consejo de Ministros por los que se 
iniciales sobre el estado de alarma: 1) se fundamenta en el art. 4 b) Ley Orgánica 4/1981 ("Crisis sanitarias, tales como epidemias y situaciones de contaminación graves»); 2) su duración fue, tras sucesivas prórrogas, del 14 de marzo al 21 de junio de 2020; y 3) según la exposición de motivos, la medidas adoptadas, necesarias y proporcionales a la gravedad situacional, no supusieron «la suspensión de ningún derecho fundamental, tal y como prevé el artículo 55 de la Constitución» respecto al estado de alarma ${ }^{70}$.

En consecuencia, el estado de alarma se perfila como una institución que, proclamada oficialmente, no permite suspender derechos y libertades - como sí, por ejemplo, el estado de excepción—, ya que, aparentemente, las medidas restrictivas que permite adoptar el art. 11 de la Ley Orgánica $4 / 1981^{71}$ no tienen tal orientación. Puede parecer lógico y presumible que, no siendo admisible que un estado de alarma suspenda derechos y libertades constitucionales, la adopción del RD 463/2020 no se haya considerado como un acto jurídico susceptible de exigir la invocación del art. $15 \mathrm{CEDH}$.

Idea coherente con los términos de la declaración interpretativa de España al ratificar el $\mathrm{CEDH}^{72}$ : «Las disposiciones de los artículos 15 y 17 [del CEDH], en el sentido de que permiten la adopción de las medidas contempladas en los artículos 55 y 116 de la Constitución Española». Esta declaración meramente interpretativa (McRae, 1978: 162-163) —en apariencia no constitutiva de una reserva de modificación como sí se ha señalado (Gonzalez 2007, 94) ${ }^{73}$-,

prohibían, respectivamente, los vuelos directos con la República Italiana y la entrada de buques de pasaje procedentes de ese país en puertos españoles. Arts. 17, 18(2) y (3), 19, 20(1) a) y d), y (5), 21, 28(2) y 37(2).

71 Se puede acordar: 1) limitar la circulación o permanencia de personas o vehículos en horas y lugares determinados, o condicionarlas a ciertos requisitos; b) practicar requisas temporales de todo tipo de bienes e imponer prestaciones personales obligatorias; 3) intervenir y ocupar transitoriamente industrias, fábricas, talleres, explotaciones o locales de cualquier naturaleza, con excepción de domicilios privados; 4) limitar o racionar el uso de servicios o el consumo de arts. de primera necesidad; y 5) impartir las órdenes necesarias para asegurar el abastecimiento de los mercados y el funcionamiento de los servicios de los centros de producción en caso de desabastecimiento. El art. 12.1, para situaciones de crisis sanitaria, permite adoptar también «las establecidas en las normas para la lucha contra las enfermedades infecciosas».

72 BOE, núm. 243, de 10 de octubre de 1979.

73 Una reserva de modificación pretende «modificar los efectos jurídicos de ciertas disposiciones del tratado en su aplicación a ese Estado» [art. 2.1.(d) de la Convención de Viena sobre el Derecho de los Tratados, de 23 de mayo de 1969], lo que sí es factible a partir de una declaración interpretativa cualificada que, además, tiende a condicionar el consentimiento estatal (McRae, 1978: 161-162). 
interpreta y precisa que las instituciones del ordenamiento jurídico español que se corresponden con las facultades del art. $15 \mathrm{CEDH}$, y, por tanto, en principio ajustadas a sus exigencias jurídicas (Roca 2019, 62), son el estado de excepción y el estado de sitio. Desde este prisma, no se antoja jurídicamente lógica la hipótesis — pudiéndose considerar como anómala (Roca 2019, 59) - de que España invocase el art. $15 \mathrm{CEDH}$ a partir de la declaración de un estado de alarma ${ }^{74}$; claro está que, en principio, nada debería llevar racionalmente a pensar tampoco que las medidas adoptadas conforme al estado de alarma excedan de lo que, a tenor del $\mathrm{CEDH}$ y sus protocolos, pueden tenerse por restricciones ordinarias.

La aproximación desde la óptica material del art. $15 \mathrm{CEDH}$ puede no ser coincidente: antes de su progresiva atenuación durante el proceso de desescalada, no parece claro que todas las medidas del RD 463/2020 pudieran ser calificadas como restricciones ordinarias en el sentido del CEDH y sus protocolos (a diferencia del ámbito interno). Esta hipótesis, vista la no invocación del art. $15 \mathrm{CEDH}$-ni, aparentemente, que la misma pudiese tener lugar conforme al RD 463/2020 — comportaría la supervisión de las medidas adoptadas con ocasión del estado de alerta desde los parámetros de necesidad y proporcionalidad propias de la aplicación ordinaria del CEDH y sus protocolos. En este sentido, cabe preguntarse si, como puede potencialmente ser sostenido (Petit de Gabriel, 2020), el alcance del margen de apreciación podría decantar el balance en favor de la actuación estatal.

El parámetro diferencial quizá sea la proximidad o no a la lógica de la presencia de una amenaza excepcional (sanitaria) de la necesidad y proporcionalidad de las medidas restrictivas. Mientras hay medidas restrictivas ordinarias que se antojan potencialmente adecuadas a cualquier crisis sanitaria - por ejemplo, la posible exigencia de prestaciones personales obligatorias (art. $4.3 \mathrm{CEDH})^{75}$-, respecto a otras puede surgir la duda de si son más bien necesarias y proporcionales solo ante situaciones encuadrables en el art. 15

Por el contrario, una declaración meramente interpretativa, implica la intención de señalar una pauta interpretativa o aclaratoria a los efectos de la aplicación de las disposiciones convencionales afectadas al Estado que la formula (McRae, 1978: 161).

$74 \mathrm{Ni}$ que pueda inferirse que las decisiones adoptadas a través y tras el RD 463/2020 «made public the Government's intentions as regards derogation» en orden a la consideración posible de su idoneidad como fórmula de proclamación oficial (Brannigan and McBride v. the United Kingdom, 26 May 1993, párr. 73, Series A no. 258-B).

75 Ante la falta de desarrollo durante el estado de alarma de las previsiones de la Orden SND/297/2020, de 27 de marzo, del Ministerio de Asuntos Económicos y Transformación Digital ( $B O E$, núm. 86, de 28 de marzo) no se abordará el asunto del derecho a la intimidad y las aplicaciones en móviles (art. $8 \mathrm{CEDH}$ ). 
$\mathrm{CEDH}$, excediendo los parámetros de necesidad y proporcionalidad de las restricciones ordinarias ${ }^{76}$. Hay que resaltar aspectos como su intensidad, su generalización a todo o a la mayoría del universo poblacional, o su injerencia significativa en el contenido esencial del derecho o libertad.

Sin ánimo de exhaustividad, ni de llegar a conclusiones definitivas, se reflexiona sobre los siguientes supuestos a la luz del RD 463/2020:

- La suspensión de la actividad educativa presencial (art. 9) podría entenderse, atendiendo a la alternativa sustitutoria de la actividad a distancia, que llega o no a "curtail the right in question to such an extent as to impair its very essences ${ }^{77}$.

- La disposición adicional segunda dispone la suspensión de plazos procesales. La incertidumbre está en si su incidencia general sobre gran parte de la actividad judicial ha comportado afecciones en garantías e intereses, así como desigualdades de trato, susceptibles de constituir restricciones del ejercicio del derecho a un juicio equitativo (art. $6 \mathrm{CEDH}$ ) que, ponderadas desde el prisma institucional ordinario, atacan o no la «essence of the right» (European Court of Human Rights, 2020: 15, párr. 52) ) $^{78}$.

La suspensión de las comunicaciones y permisos a todos los presos, a tenor del art. $8 \mathrm{CEDH}$, podría considerase desproporcionada como restricción ordinaria al no plantearse otras opciones menos severas y generalizarse a todo centro penitenciario sin distinción alguna en función de la situación particular de cada uno ${ }^{79}$.

Es perceptible cómo el RD 463/2020 establece medidas temporales que implican, en el sentido del art. 1 Protocolo adicional primero, interferencia en el goce de bienes privados.

Algunas de las medidas restrictivas no parecen, si son aplicadas con proporcionalidad, insostenibles como restricciones ordinarias: requisas

76 La referencia básica en materia sanitaria, dejando de lado la legislación autonómica, serían los arts. 25 y 26 Ley 14/1986, de 25 de abril, General de Sanidad y la Ley Orgánica 3/1986, de 14 de abril, de Medidas Especiales en Materia de Salud Pública.

77 Leyla Şahin v. Turkey [GC], no. 44774/98, párr. 154, ECHR 2005-XI

78 Lo mismo podría decirse debido a la suspensión de plazos administrativos (disposición adicional tercera), considerando la aplicabilidad a algunos procedimientos administrativos, por ejemplo, los de carácter sancionador.

79 Orden INT/227/2020, de 15 de marzo, en relación con las medidas que se adoptan en el ámbito de Instituciones Penitenciarias al amparo del Real Decreto 463/2020, de 14 de marzo, por el que se declara el estado de alarma para la gestión de la situación de crisis sanitaria ocasionada por el COVID-19 (BOE, núm. 68, de 15 de marzo 2020). 
temporales de bienes obligatorias (art. 8), medidas para garantizar abastecimiento de bienes y servicios para la protección de la salud pública o alimentos $^{80}$ (arts. 13 o 15).

No parece tan fácil sostener la inclusión entre ellas de la suspensión de «la apertura al público de los locales y establecimientos minoristas» — salvo las excepciones establecidas-, hosteleros y de restauración — salvo para entregas a domicilio (art. 10) - ${ }^{81}$. La grave afección a bienes incorporales (Sudre, 2015: 837), como el mantenimiento de la clientela ${ }^{82}$ o el interés económico derivado de la explotación de un negocio ${ }^{83}$, plantea dudas sobre su proporcionalidad como restricción ordinaria, por el hecho del alcance de su concreción y por no explorarse otras alternativas menos lesivas para atenuar el riesgo de contagio, aun cuando habría que apreciar la importancia de las medidas socioeconómicas correctivas adoptadas $^{84}$.

Probablemente, incluida su interconexión con otras restricciones, el asunto más controvertido sea el de la inicial limitación de la libertad de circulación de las personas salvo excepciones tasadas (art. 7) ${ }^{85}$.

Más bien, parece establecerse una prohibición general de circulación de las personas $-\mathrm{y}$, por añadidura consecuencial, su confinamiento domiciliario-,

80 Pese a que, como se ha visto, pueda constituir en sí una crisis excepcional de naturaleza económica.

81 Se añade una cláusula de cierre que ofrece amplia discrecionalidad a las autoridades competentes, suspendiéndose «cualquier otra actividad o establecimiento que a juicio de la autoridad competente pueda suponer un riesgo de contagio". Van Marle and Others $v$. the Netherlands, 26 June 1986, pars. 41-42, Series A no. 101.

83 Fredin v. Sweden (no. 1), 18 February 1991, pars. 40-42, Series A no. 192.

84 En un escenario de posible excepcionalidad de naturaleza económica, en 2010, el Gobierno griego adoptó medidas legislativas de urgencia para superar la crisis financiera y sostener la economía nacional, entre las cuales había algunas que afectaban al derecho a la propiedad reconocido en el art. 1 Protocolo adicional primero, respecto a un colectivo como los funcionarios públicos. El TEDH consideró que las medidas restrictivas del goce pacífico de los bienes consistentes en el recorte de sueldos y pensiones de los funcionarios griegos (párr. 1 del citado artículo) eran proporcionales, puesto que, teniendo en cuenta el margen de apreciación del Estado, no comportaban una excesiva carga para los demandantes —al no implicar que quedasen desprovistos tras el recorte de medios suficientes de vida-, frente al interés público derivado de la constatación de que el Estado se encontraba en una «exceptional [financial] crisis without precedent» [Ioanna Koufaki et ADEDY contre la Grèce (dec.), nos. 57665/12 et 57657/12, \$37, 7 Mai 2013].

85 No se entrará en el tema de la circulación de vehículos por su accesoriedad y en el de las limitaciones al transporte público (art. 14). 
de naturaleza suspensiva, que puede aparentemente exceder de los presupuestos teleológicos de las restricciones ordinarias del art. 2 Protocolo núm. 4, debido a la más estricta conformación personal y/o física de las mismas (Gerards, 2018: 936-941): no se parte de la libertad de circulación para indicar unas excepciones limitativas, sino que, implícitamente, se prohíbe circular libremente salvo en las excepciones que facultan a hacerlo.

La derivación de la obligación de confinarse podría vincular subsidiariamente el art. 7 RD 463/2020 al art. 5.1(e) CEDH, aunque también parece que su alcance restrictivo de la libertad personal es desbordado: se está ante un confinamiento general por razón de salud pública que, además, prescindiría de lo prevenido por la ley, conforme al art. 5.1 CEDH: no se prevé la autorización o ratificación judicial ${ }^{86}$.

El TEDH, respecto al derecho de reunión (art. $11 \mathrm{CEDH}$ ), ha afirmado que el Estado parte debe «refrain from applying unreasonable indirect restrictions upon that right ${ }^{87}$; siendo una de ellas la privación de la libertad de movimiento para reunirse (Sudre, 2015: 525). La Subdelegación del Gobierno en Pontevedra manifestó, al evaluar una comunicación para celebrar una manifestación el 1 de mayo, que el RD 463/2020 establecía una «limitación general para circular» respecto a la que no existía una excepción para «los desplazamientos con el fin expuesto ${ }^{88}$. Aunque el Tribunal Constitucional asumiera que del RD 463/2020 no se infiere tal prohibición o suspensión (arts. 21 o $28 \mathrm{CE}$ ) y sí de la «interpretación del alcance de tal mecanismo de excepcionalidad por la Administración ${ }^{89}$, desde el prisma del CEDH y sus protocolos sus efectos pueden entenderse como suspensivos, con carácter general, del derecho de reunión por derivación de la prohibición general de circulación. No ocurre lo mismo respecto a la libertad de manifestar la propia

86 El art. 8.6 de la Ley de la Jurisdicción Contencioso-Administrativa establece que es competencia del juez de lo Contencioso-Administrativo «la autorización o ratificación judicial de las medidas que las autoridades sanitarias consideren urgentes y necesarias para la salud pública e impliquen privación o restricción de la libertad o de otro derecho fundamental». Así, por ejemplo, se ha señalado, al justificar medidas semejantes acabada la vigencia del estado de alarma, que cuando las medidas sanitarias ante un riesgo para la salud pública que competen a la Administración afectan «al ámbito de derechos fundamentales y libertades, se exige el control judicial, que actúa en estos casos, no en ejercicio de potestades jurisdiccionales sino de garantía en los términos del art. 117.4 CE» (Auto 130/2020 del Juzgado Contencioso-Administrativo no 2 de Santiago de Compostela, de 7 de julio 2020, F.D. Tercero [ECLI: ES:JCA:2020:31 a]). Djavit An v. Turkey, no. 20652/92, párr. 57 ECHR 2003-III.

88 ATC 40/2020, de 30 abril 2020, Antecedente de Hecho $2^{\circ}$.

89 Ibid., FJ $4^{\circ}$. 
religión (art. $9 \mathrm{CEDH}$ ), pues el art. $11 \mathrm{RD}$ 463/2020 no cierra la posibilidad, sino que la condiciona a medidas organizativas ${ }^{90}$.

Durante el estado de alarma se ha debatido sobre la gestión pública de la pandemia: control de la expansión de la pandemia, tratamiento de los pacientes o la disponibilidad de bienes de detección y protección para sanitarios y otras personas. Al aludir a obligaciones positivas vinculadas a los arts. 2 y $3 \mathrm{CEDH}$ (derechos inderogables), esto abre la perspectiva de cómo abordar el grado de cumplimiento en función de la calificación de la crisis sanitaria y del escenario de supervisión diferenciado. Más allá de la ponderación de todos los elementos en juego, cabe preguntarse si, en buena medida, la generalización e intensidad de algunas de las medidas restrictivas adoptadas con el fin de controlar la pandemia, no responden a una falta de disponibilidad de recursos y materiales, incluso de la diligencia debida, para cumplir con las obligaciones positivas mediante medidas generalmente menos invasivas. Además, las insuficiencias en cuanto a la protección del personal sanitario y ciudadanía permiten preguntarse: 1) si pueden relacionarse con los arts. 3 y 11 CSE - derechos a la seguridad e higiene en el trabajo y a la protección de la salud-conforme a la jurisprudencia del Comité Europeo de Derechos Sociales (Council of Europe, 2018: 233); y 2) si no tendría sentido invocar la cláusula derogatoria del art. 30 CSE/art. F CSE revisada - lo que ningún Estado ha hecho-.

\section{CONSIDERACIONES FINALES}

La posibilidad de calificar la crisis sanitaria generada por la COVID-19 como una amenaza excepcional en el sentido de la cláusula derogatoria del art. $15 \mathrm{CEDH}$ se ha demostrado como no descartable, atendiendo: a los criterios interpretativos establecidos por los órganos de supervisión del CEDH; al nivel de riesgo sanitario (interno y global) existente; y a la práctica de un número minoritario pero significativo de diez Estados partes que han invocado el art. $15 \mathrm{CEDH}$.

La invocación de la cláusula derogatoria permite disponer de un amplio margen de apreciación para justificar la necesidad y proporcionalidad de las medidas de injerencia en los derechos y libertades reconocidos en el CEDH y sus protocolos adoptadas ante una amenaza excepcional; las

90 Por ejemplo, la Orden SND/298/2020, de 29 de marzo, por la que se establecen medidas excepcionales en relación con los velatorios y ceremonias fúnebres para limitar la propagación y el contagio por el COVID-19 (BOE, núm. 88, 30 de marzo 2020). 
medidas derogatorias, legítimas ante tal situación de hecho, tienden a ser más intrusivas (por suspensivas) que las restricciones ordinarias previstas en las disposiciones específicas del CEDH y sus protocolos para situaciones propias de normalidad democrática.

La hipótesis de que un Estado parte pueda prevalerse de tipologías de medidas derogatorias más próximas a los parámetros de la excepcionalidad que a las restricciones ordinarias, o que combine unas y otras para atajar la pandemia, plantea dos cuestiones:

- la posibilidad de que, entre los Estados que no invoquen la cláusula derogatoria, los haya que estén adoptando medidas derogatorias desde la perspectiva de la interpretación del $\mathrm{CEDH}$ y sus protocolos; ante una futura intervención del TEDH, ello supone que la conducta estatal será evaluada (necesidad y proporcionalidad) bajo los parámetros de disposiciones convencionales específicas que autorizan la restricción ordinaria;

- la diferenciación entre unas y otras medidas, operación compleja a la que este estudio se ha aproximado comparativamente y a través del caso español, precisa de una investigación profunda y detallada; particularmente, porque no existe práctica jurisdiccional sobre amenazas excepcionales sanitarias ante una casuística focalizada en las crisis políticas.

El caso español puede ser paradigmático, porque existen indicios de que se podrían haber adoptado medidas que, conforme a los parámetros del art. $15 \mathrm{CEDH}$, serían de naturaleza derogatoria (tal y como se ha señalado en el epígrafe III.3). La no invocación del art. $15 \mathrm{CEDH}$ por España, que parece responder a una sensibilidad jurídica interna basada en los términos jurídicos que definen el alcance del estado de alarma y que alejan esta institución constitucionalmente de aquellas que permiten la suspensión de derechos y libertades ( $y$, por tanto, de proceder a una proclamación oficial a tenor del art. $15 \mathrm{CEDH}$ ), señala cuál puede ser el punto de partida de una futura supervisión por el TEDH, si esta se produce: las medidas previstas conforme al estado de alarma serían enjuiciadas como restricciones ordinarias en el sentido del CEDH y de sus protocolos, desde la perspectiva de su necesidad y proporcionalidad — disponiéndose a priori de un margen de apreciación menos amplio que en caso de invocarse la cláusula derogatoria, sin perjuicio de que es obvio que el TEDH puede a partir del mismo ser comprensivo con la actuación estatal ante el balance a efectuar-. En todo caso, la indefinición actual de la línea divisoria entre una y otra tipología de medidas para abordar la pandemia desde el prisma del CEDH y sus protocolos no permite predecir a priori consecuencia jurídica alguna, inequívoca y definitiva, ante posibles demandas ante el TEDH. 


\section{Bibliografía}

Boletín Oficial del Estado (2020). COVID-19: Derecho Europeo, Estatal y Autonómico (actualizado a 7 de octubre de 2020). Disponible en: https://bit. ly/3e14nXb.

Born, G., Morris, D., and Forrest, S. (2020). Margin of appreciation: Appreciating its irrelevance in international law. Harvard International Law Journal, 61(1), 65-134.

Cançado-Trindade, A. A. (1996). The Case-Law of the International Court of Justice on Non-Derogable Rights. En D. Prémont, C. Stenersen, L. Oseredczuk, I. Droits Intantibles et Etats d'Exception/Non-Derogable Rights and States of Emergency (pp. 73-90). Bruxelles: Bruylant.

Carrillo Salcedo, J. A. (2009). The European Convention on Human Rights. En F. Gómez, K. De Feyter (eds.). International Human Rights Law in a Global Context (pp. 631-687). Bilbao: University of Deusto.

Casadevall, J. (2012). El Convenio Europeo de Derechos Humanos, el Tribunal de Estrasburgo y su jurisprudencia. Valencia: Tirant lo Blanch.

Comité de Derechos Humanos (1981). Observación general núm. 5. Suspensión de las obligaciones (artículo 4). Documento HRI/GEN/1/Rev.9 (Vol.I), 27 de mayo de 2008.

- (2001). Observación general núm. 29. Estados de emergencia (artículo 4). En ONU. Recopilación de las Observaciones Generales y Recomendaciones adoptadas por los órganos creados en virtud de tratados de derechos humanos. Documento CCPR/C/21/Rev.1/Add.11, 31 de agosto de 2001.

- (2007). Observaciones finales del Comité de Derechos Humanos. Georgia. Documento CCPR/C/GEO/CO/3, 15 de noviembre 2007. Disponible en: https://doi.org/10.5354/0718-2279.2007.13484.

Costa, J.-P. (2020). Le recours à l'article 15 de la Convention européenne des droits de l'homme. Le Club des Juristes [blog], 27-4-2020. Disponible en: https://bit. ly/37EYspI.

Council of Europe (1956). Preparatory Work on Article 15 of the European Convention on Human Rights. Information document prepared by the Secretariat of the Commission at the request of the President of the Commission. Document DH (56) 4, 22 May 1956.

- (2018). Digest of the Case-Law of the European Committee of Social Rights, December 2018. Disponible en: https://bit.ly/34woDgg.

- (2020a). Treaty Office. Notifications under Article 15 of the Convention in the context of the COVID-19 pandemic. Disponible en: https://bit.ly/3oysBga.

- (2020b). Treaty Office. Search on States and International Organisations Search for a list of declarations for a given State or International Organisation. Disponible en: https://bit.ly/2G0XI2D. 
- (2020c). Respecting democracy, rule of law and human rights in the framework of the COVID-19 sanitary crisis. A toolkit for member states. Document SG/ Inf(2020)11, 4 April 2020. Disponible en: https://bit.ly/3e0f3Fo.

Desierto, D. A. (2012). Necessity and National Emergency Clauses. Sovereignty in Modern Treaty Interpretation. Leiden: Martinus Nijhoff Publishers. Disponible en: https://doi.org/10.1163/9789004218536.

Dzehtsiarou, K. (2020). COVID-19 and the European Convention on Human Rights. Strasbourg Observers [blog], 27-3-2020. Disponible en: https://bit. ly/3jr1PTq.

European Court of Human Rights (2015). Health-related issues in the case-law of the European Court of Human Rights. Strasbourg: Council of Europe. Disponible en: https://bit.ly/31LvDnO.

- (2019). Guide on Article 15 of the European Convention on Human Rights. Derogation in time of emergency. Strasbourg: Council of Europe. Disponible en: https://bit.ly/2Hz55Pk.

- (2020). Guide on Article 6 of the European Convention on Human Rights. Right to a fair trial (criminal limb). Strasbourg: Council of Europe. Disponible en: https://bit.ly/3jFNJxL.

El Zeidy, M. M. (2003). The ECHR and States of Emergency: Article 15 - A Domestic Power of Derogation from Human Rights Obligations. San Diego International Law Journal, 4, 277-318.

Fitzpatrick, J. (1994). Human rights in crisis: the international system for protecting rights during states of emergency. Philadelphia: University of Pennsylvania Press. Disponible en: https://doi.org/10.9783/9781512815924.

Gerards, J. (2018). Freedom of Movement. En P. Van Dijk, P. Van Hoof, A. Van Rijn, L. Zwaak (eds.). Theory and practice of the European Convention on Human Rights (pp. 933-944). Cambridge: Intersentia.

Gonzalez, G. (2007). L'état d'urgence au sens de l'article 15 de la Convention européenne des droits de l'homme. $C R D F, 4,93-100$.

Government of Georgia (2006). Joint Briefing Held after Georgian Government Session on February 24, 2006. Disponible en: https://bit.ly/3ouSBsS.

Greene, A. (2020). States should declare a State of Emergency using Article 15 ECHR to confront the Coronavirus Pandemic. Strasbourg Observers [blog], 1-4-2020. Disponible en: https://bit.ly/37JLdnv.

Gross, O. and Aolaín, F. N. (2006). Law in Times of Crisis. Emergency Powers in Theory and Practice. Cambridge: Cambridge U. Press.

Gudzenko, M. (2020). Quelle immunité des droits de l'homme face à la pandémie ? À propos de la valeur ajoutée de la dérogation prévue à l'article 15 de la Convention européenne des droits de l'homme. Confluence des droits_La revue [En ligne], núm. 07. Disponible en: https://confluencedesdroits-larevue. $\mathrm{com} / \mathrm{p}=1239$.

Hartman, J. F. (1981). Derogation from human rights treaties in public emergencies -a critique of implementation by the european commission and court of human 
rights and the human rights committee of the united nations. Harvard International Law Journal, 22 (1), 1-52.

Holcroft-Emmess, N. (2020). Derogating to Deal with Covid 19: State Practice and Thoughts on the Need for Notification. EJIL:Talk! [blog],10-4-2020. Disponible en: https://bit.ly/2TsXyUW.

Kadelbach, S. (2017). The Right to Invoke Rights as a Limit to Sovereignty -Security Interests, State of Emergency and Review of un Sanctions by Domestic Courts under the European Convention of Human Rights. Nordic Journal of International Law, 86, 275-301. Disponible en: https://doi.org/10.1163/1571810708603003.

Kushtrim, I. and Salomon, S. (2019). Entrenched Derogations from the European Convention on Human Rights and the Emergence of Non-Judicial Supervision of Derogations. Austrian Review of International and European Law Online, 22, 7-28. Disponible en: https://doi.org/10.1163/15736512-02201003.

Law Commission (2011). Final Report on Emergencies. Parliament of New Zealand, Report $n^{\circ} 22$.

McRae, D. M. (1978). The Legal Effect of Interpretative Declarations. British Yearbook of International Law.49, 155-174. Disponible en: https://doi.org/10.1093/ bybil/49.1.155.

Lillich, R. B. (1985). The Paris Minimum Standards of Human Rights Norms in a State of Emergency. American Journal of International Law, 79(4), 1072-1081. Disponible en: https://doi.org/10.2307/2201848.

Makszimov, V. (2020). Coronavirus derogations from human rights send wrong signal, say MEPs. EURACTIV.com, 24 mars 2020. Disponible en: https://bit. ly/3oxiYhS.

Mariniello, T. (2019). Prolonged emergency and derogation of human rights: Why the european court should raise its immunity system. German Law Journal, 20(1), 46-71. Disponible en: https://doi.org/10.1017/glj.2019.3.

McBride, J. (2020). An Analysis of Covid-19 Responses and ECHR Requirements. ECHR Blog, 27-3-2020. Disponible en: https://bit.ly/3jFPevT.

Mowbray, A. (2004). The Development of Positive Obligations under the European Convention on Human Rights by the European Court of Human Rights. Oxford: Hart Publishing,

Naciones Unidas (1985). Nota verbal de fecha de 24 de agosto de 1984 enviada al Secretario General por el Representante Permanente de los Países Bajos ante la Oficina de las Naciones Unidas en Ginebra. Documento E/CN.4/1985/4, de 28 de septiembre de 1984 .

- (1997). Décimo informe anual y lista de Estados que desde el $1^{\circ}$ de enero de 1985 han proclamado, prorrogado o levantado el estado de excepción, presentado por el Sr. Leandro Despouy, Relator Especial, nombrado en cumplimiento de la resolución 1985/37 del Consejo Económico y Social. Documento E/CN.4/ Sub.2/1997/19, de 29de junio de 1997.

Negri, S. (2018). Communicable disease control. En G. L.Burci, B. Toebes, (eds.). Research Handbook on Global Health Law (pp. 265-302). Cheltenham: Edward 
Elgar Publishing. Disponible en: https://doi.org/10.4337/9781785366543.00 018.

Neuman, G. L. (2016). Constrained Derogation in Positive Human Rights Regimes. En E. C. Criddle (ed). Human Rights in Emergencies (pp. 15-31). Cambridge: Cambridge University Press. Disponible en: https://doi.org/10.1017/ CBO9781316336205.002.

OMS (2005). Respuesta a la amenaza de una pandemia de gripe aviar. Medidas estratégicas recomendadas. Documento WHO/CDS/CSR/GIP/2005.8, p. 1

- (2009). Declaración de la Directora General de la OMS 25 de abril de 2009.

- (2018). Notas Descriptivas. Virus de la gripe aviar y otros virus de la gripe de origen zoonótico. Disponible en: https://bit.ly/3owdd4g.

- (2020). Alocución de apertura del Director General de la OMS en la rueda de prensa sobre la COVID-19 celebrada el 11 de marzo de 2020. Disponible en: https://bit.ly/2J6XxUF.

Oraá Oraá, J. (1992). Human Rights in States of Emergency in International Law, Oxford: Clarendon Press.

Petit de Gabriel, E. W. (2020). España y el Convenio Europeo de Derechos Humanos en tiempos de pandemia: ¿Derogación, limitación o violación de derechos fundamentales? Aquiescencia. Blog de Derecho Internacional, 30-4-2020. Disponible en: https://bit.ly/3jE9i1G.

Roca, M. J. (2019). La suspensión del Convenio Europeo de Derechos Humanos desde el Derecho Español: procedimiento y control. Revista Española de Derecho Europeo, 72, 43-72. Disponible en: https://doi.org/10.2307/j.ctv153k4cz.8.

Schabas, W. A. (2015). The European Convention on Human Rights. A Commentary. Oxford: Oxford University Press.

Scheuerman, E. (1999-2000). The Economic State of Emergency. Cardozo Law Review, 21, pp. 1869-1894.

Sistema de Vigilancia de la Gripe en España (2006). Infección por H5N1 en seres humanos. Actualización 13-03-2006 y Infección por H5N1 en aves: situación en la Unión Europea y fuera de ella. Actualización a 13 de marzo de 2006. Disponibles en: https://vgripe.isciii.es/inicio.do.

Sottiaux, S. (2018). Derogation intime of Emergency. En P. Van Dijk, P. Van Hoof, A. Van Rijn, L. Zwaak. (eds.). Theory and practice of the European Convention on Human Rights (pp. 1063-1076). Cambridge: Intersentia.

Sudre, F. (2015). Droit européen et international des droits de l'homme. Paris: Puf.

- (2020). La Convention EDH face au Covid-19: dépasser les apparences. Le Club des Juristes [blog] 27-4-2020. Disponible en: https://bit.ly/3mrO9cy.

Svensson-McCarthy, A.L. (1998). The International Law of Human Rights and the States of Exception. With Special References to the Travaux Préparatoires and the Case-Law of the International Monitoring Organs. The Hague: Martinus Nijhoff Publishers.

Toullier, M. (2017). The European court of human rights 'control over states' derogation in time of emergency: Example of effectiveness of the lessons learned from WW2. International Comparative Jurisprudence, 3(1), 8-24. 
United Nations (1982). Study of the implications for human rights of recent developments concerning situations known as states of siege or emergency (Special Rapporteur: Mrs. N. Questiaux). Document E/CN.4/Sub.2/l982/15, 27 July 1982.

- (2005). International Covenant on Civil and Political Rights. Nicaragua: Notification under Article 4 (3), C.N.523.2005.TREATIES-11 (Depositary Notification), p. 3. Disponible en: https://bit.ly/34wX4Dt.

Vaquerizas Pulido, J. I. (2020). La protección del derecho a la vida en el contexto del Covid-19 desde la perspectiva del artículo 2 del Convenio Europeo de Derechos Humanos. Revista de Derecho vLex, 194, 1-12.

Zghibarta, P. (2020). The Whos, the Whats, and the Whys of the Derogations from the ECHR amid Covid-19. EJIL:Talk! [blog], 11-4-2020. Disponible en: https://bit.ly/3dZLJis.

Zoethout, C. M. (2014). Margin of Appreciation, Violation and (in) Compatibility: Why the ECtHR Might Consider Using an Alternative Mode of Adjudication. European Public Law, 20 (2), 309-330.

Zovatto, D. G. (1988). La interpretación del artículo 27 de la Convención Americana sobre Derechos Humanos en las opiniones consultivas de la Corte Interamericana de Derechos Humanos. Revista del Instituto Interamericano de Derechos Humanos, 7, 43-65. 